\title{
Taksi Yolculuğu İçin Geliştirilmiş Mobil Uygulamalarda Süreç Modelleri: Yolcu Hakimiyeti Açısından Eksikler ve Yeni Bir Model Önerisi
}

\author{
Yılmaz Kemal Yüce ${ }^{*}$, Ali Çoban², Şerif İnanır ${ }^{3}$ Yalçın İşler ${ }^{4}$ \\ 1* Alanya Alaaddin Keykubat Üniversitesi, Rafet Kayış Mühendislik Fakültesi, Bilgisayar Mühendisliği Bölümü, Antalya, Türkiye, (ORCID: 0000-0001-5291-0565), \\ yilmazkemalyuce@gmail.com \\ ${ }^{2}$ Gazi Üniversitesi, Mühendislik Fakültesi, Bilgisayar Mühendisliği Bölümü, Ankara, Türkiye (ORCID: 0000-0002-0372-7737), cobanali978@ gmail.com \\ ${ }^{3}$ Yıldız Teknik Üniversitesi, Elektrik-Elektronik Fakültesi, Bilgisayar Mühendisliği Bölümü, İstanbul, Türkiye (ORCID: 0000-0003-3761-3751), \\ sheriffnnr@gmail.com \\ ${ }^{4}$ İzmir Katip Çelebi Üniversitesi, Mühendislik Fakültesi, Biyomedikal Mühendisliği Bölümü, İzmir, Türkiye (ORCID: 0000-0002-2150-4756), islerya@ yahoo.com
}

(International Conference on Design, Research and Development (RDCONF) 2021 - 15-18 December 2021)

(DOI: 10.31590/ejosat.1045908)

ATIF/REFERENCE: Yüce, Y. K., Çoban, A., İnanır, Ş. \& İşler, Y. (2021). Taksi Yolculuğu İçin Geliştirilmiş Mobil Uygulamalarda Süreç Modelleri: Yolcu Hakimiyeti Açısından Eksikler ve Yeni Bir Model Önerisi. Avrupa Bilim ve Teknoloji Dergisi, (32), 403-413.

Öz

Taksi yolculuğu için geliştirilmiş birçok yazılım mobil uygulama marketlerinde yer almaktadır. İlgili uygulamalar yolculuk hâkimiyeti ve kontrolü için çeşitli işlem ve işlevler barındırmaktadır. Bu çalışmada, taksi yolculuğunu kontrol altına alan uygulamalar incelenmiştir. İnceleme sonucunda uygulamaların benimsediği süreç modeli ve işlev-işlem kümeleri ortaya çıkarılmıştır. Böylece yolculuk için jenerik bir model ortaya konmuştur. Jenerik model, taksi yolculuğunu bütüncül bir şekilde ele alabilecek 5 aşamaya sahiptir: yolculuk tasarlama, yolculuk eşleştirme, taksi bekleme, yolculuk seyir takibi ve yolculuk sonrası. İncelenen uygulamaların işlev ve işlemleri birbirleriyle karşılaştııılmıştır. Karşılaştırma sonucunda yurtiçi ve yurtdışı mobil uygulamaların işlevsellikleri arasındaki farklar ortaya konmuștur. Çalışmanın diğer bir amacı ise, mobil uygulamalar için yeni bir taksi yolculuk hizmet modeli tasarlamaktır. Bu modelin önemli yönü, incelenen uygulamalarda bulunmayan işlemlere de dayalı olarak yolcuların yolculuklarının her aşamasında hakimiyetlerini artırmak üzere tasarlanmasıdır. İlgili işlemler sayesinde yolculuk esnasında rota üzerinde düzenlemeler yapılabilir. Gelecek çalışma niteliğinde olmak üzere, çalışmadaki önerilen model kapsamında taksi ulaşımı için bir konuma dayalı yolcu bilgilendirme mobil uygulamasının geliştirilmesi planlanmaktadır.

Anahtar Kelimeler: Konuma dayalı hizmetler, akıllı ulaşım sistemleri, kent içi ulaşım, taksi, yolcu bilgilendirme sistemleri.

\section{Process Models in Mobile Applications Developed for Cab Journey: Deficiencies in Passenger Control and a New Model Suggestion}

\begin{abstract}
Many applications software developed for taxi travel is available in mobile application markets. Related mobile applications contain various operations and functions for journey control. In this study, the applications that control the taxi journey are investigated. As a result of this investigation, the process model and operation-function clusters used by the applications were revealed. Thus, a generic model for the journey was revealed. The generic model has 5 stages that can handle the taxi journey holistically: Journey Design, Journey Matching, Taxi Waiting, Journey Tracking, and Post Journey. The operations and functions of the examined applications were compared with each other. As a result of the comparison, the differences among the functionalities of local (for Turkey) and international mobile applications were revealed. Another aim of the study is to design a new taxi journey service model. The important aspect of this model is that it has a function that is not found in other applications which were examined under review. Thanks to the related function, route regulations can be made during taxi journey. As a future study, it is planned to develop a location-based passenger information mobile application for taxi transportation within the scope of the proposed model in the study.
\end{abstract}

Keywords: Location-based services, Smart transportation systems, Urban transportation, Cab, Taxi, Passenger information systems

\footnotetext{
*Sorumlu Yazar: yilmazkemalyuce@gmail.com
} 


\section{Giriş}

Ulaşım, gün geçtikçe genişleyen kentlerde ve küçük-büyük tüm yaşam alanları arasında, giderek büyüyen bir sektör olarak karşımıza çıkıyor. Hızla elektronikleşen dünyada, farklı alan ve sektörler için, hizmet sunma ve almada bugün hâlâ bir temel faaliyet ve gereklilik olma özelliğini koruyor. Büyük ve yüksek nüfuslu kentlerde toplu taşıma, başta maliyet olmak üzere, birçok açıdan iyi bir seçenek olarak kabul görse de geçmişten gelen sorunları, hızlı ulaşım çözümüne uygun olmayışı, pratikte çözüm için gerektirdiği eforun yanında, bugün CoVid-19'un sebep olduğu yeni normal dikkate alındığında taksi ile ulaşım daha cezbedici bir seçenek olarak karşımızda duruyor.

Taksi ile yolculuk, diğer ulaşım alternatifleri ile karşılaştırıldığında daha düşük enfeksiyon riski taşıyan bir seçenek olarak algılanabilmesinin yanında, görece hızlı çözüm gerektiren ulaşım problemlerinde alternatif bir çözüm olarak uygulanabilirliği ile de öne çıkmaktadır [1].

2019 itibariyle Türkiye'de 75 bine yakın ticari taksi bulunmaktadır [2]. Bu araçlardan 7701 tanesinin Ankara'da, 2823'ünün İzmir'de kayıtlı olduğu bildirilmiştir [3]. İstanbul ise ticari taksi sayısında başı çekmektedir. İstanbul Taksi Esnaf Odası'nın verilerine ve İstanbul Büyükşehir Belediyesi'nin (İBB) 2017 yılına dair Ulaşım Raporu'na göre İstanbul'da 17 bin $395(\% 23,2)$ kayıtlı ticari taksi bulunmaktadır [4].

İstanbul'un farklı yıllara ait ulaşım istatistikleri Tablo 1'de görülmektedir [5]. İBB'nin 2016 yılına ilişkin verdiği ulaşım istatistikleri göstermektedir ki 2016'da 14,6 milyon nüfusu olan İstanbul'da günde ortalama 10 milyonun üzerinde (10 milyon 243 bin 738) kişi ulaşımını karayoluyla yapmıştır. Bunlarınsa 1 milyon 675 bin 824'ünün yolculuklarını taksi ve taksi dolmuş aracılığıly yaptığı bilinmektedir $(\% 16,35)$ [6]. Yine İBB'nin 2019 yılına ilişkin sağladığı ulaşım istatistiklerine göre ortalama günlük yolcu sayısı 16 milyon 611 bin 391'dir. Bunlardan, karayolunu tercih eden günlük yolcu sayısı 12 milyon 401 bin 120 'dir $(\% 74,65)$. Karayolunu tercih edenlerden ise 1 milyon 403 bin 949'u $(\% 11,32)$ taksi ve taksi dolmuş ile yolculuk yapmıştır [7]. Yalnız İstanbul'daki bu yüksek kapasitede kullanımla birlikte, taksi yolculuklarında farklı tipte sorunlar ve anlaşmazlıklar yaşandığı, hatta taksi şoförleri hakkında resmi ve gayri resmi şikayetler ve resmi şikayetlere ilişkin yarg1 tarafından alınan kararlarla sabit, işlenmiş suçlar olduğu da bilinmektedir [8]. 2019'da İstanbul'da taksicilerle ilgili ALO 153 Beyaz Masa'ya toplamda 179 bin 177 vatandaş şikâyet başvurusu yapmıştır [9]. Bununla birlikte sikayetvar.com platformunda basit bir arama yapıldı ğında, Taksi Şoförleri Odası'nı muhatap alan 01.01 .2020 ve 22.07.2020 tarihleri arasında taksi şoförlerine yönelik yapılan 211 şikâyet bulunmuştur.

Tablo 1. Istanbul'un yıllara göre günlük ortalama yolcu sayısı

\begin{tabular}{l|c|c|c|c}
\hline Yıl & Karayolu & $\begin{array}{c}\text { Raylı } \\
\text { Sistemler }\end{array}$ & Denizyolu & $\begin{array}{c}\text { Toplam } \\
\text { Günlük } \\
\text { Yolcu }\end{array}$ \\
\hline 2004 & $\begin{array}{c}5.437 .650 \\
(\% 87,70)\end{array}$ & 532.000 & 230.350 & 6.200 .000 \\
\hline 2009 & $\begin{array}{c}8.416 .000 \\
(\% 87,90)\end{array}$ & 881.152 & 277.809 & 9.574 .961 \\
\hline 2014 & $\begin{array}{c}9.916 .583 \\
(\% 79,27)\end{array}$ & 2.040 .489 & 552.429 & 12.509 .501 \\
\hline 2015 & $\begin{array}{c}9.918 .601 \\
(\% 77,00)\end{array}$ & 2.299 .312 & 663.387 & 12.881 .300 \\
\hline
\end{tabular}

\begin{tabular}{l|c|c|c|c}
\hline 2016 & $\begin{array}{c}10.243 .738 \\
(\% 77,79)\end{array}$ & 2.299 .040 & 625.513 & 13.168 .291 \\
\hline 2017 & $\begin{array}{c}10.793 .061 \\
(\% 78,52)\end{array}$ & 2.446 .028 & 507.140 & 13.746 .229 \\
\hline 2018 & $\begin{array}{c}11.717 .979 \\
(78,15)\end{array}$ & 2.709 .914 & 565.472 & 14.993 .365 \\
\hline 2019 & $\begin{array}{c}12.401 .120 \\
(\% 74,65)\end{array}$ & 3.401 .993 & 808.278 & 16.611 .391 \\
\hline
\end{tabular}

Söz konusu yargı kararları ve farklı platformlarda yapılan şikayetler farklı nitelik ve sebeplere dayalı olarak kategorize edilebilir. Taksi şoförlerine yönelik şikayetler arasında kısa mesafeye yolculuk nedeniyle yolcuyu almamak, belli mesafe için fazla hatta fahiş ücret almak, yolculuk sırasında sakıncalı hal, tavır, tutum ve davranış sergilemek (örneğin; yolcu ile iletişimde uygunsuz üslup kullanmak, yolcuya hakaret etmek, sigara içmek), taksimetreyi açmamak, gündüz saatlerinde gece tarifesi ile açmak ve yolculuk mesafesini uzatmak öne çıkanlar arasındadir [10].

Yolcuların sorunsuz yolculuk deneyimlemeleri, adı geçen sorunların önlenmesi ve çözümlenmesi ile mümkün olabilir. $\mathrm{Bu}$ hedefe yönelik, yolcunun yolculuk sürecine hakimiyetini artırarak daha güvenli ve güvende seyahat etmesi için farklı stratejilere dayalı ve teknolojiden faydalanan birçok mobil uygulama geliştirilmiştir [11]. Bu uygulamalar kullanıcıyı taksi yolculuğu ile ilgili olarak yolculuk öncesinde ve yolculuk boyunca takip amaçlı bilgilendirerek yolculuğunu kontrol edebileceği ve daha güvende hissedeceği bir yolculuk planlamasını ve yapmasını sağlamaktadır.

$\mathrm{Bu}$ çalışmada, söz konusu mobil uygulamalarda yolcunun yolculuğa hakimiyetini artırmak üzere kullanılan temel strateji, bu stratejiye yönelik modeller ve işlevler incelenmiştir. Bu kapsamda, taksi yolculuk hizmeti için geliştirilmiş mobil uygulamaların birçoğunun kullandığı jenerik model üzerinden hareketle mobil uygulamaların barındırdıkları imkân, işlem ve işlevler kümesi ortaya çıkarılmıştır. Söz konusu imkân, işlem ve işlevler temel alınarak uluslararası çapta en popüler taksi yolculuk hizmeti mobil uygulamaları ve Türkiye'de ulusal ve yerel çapta en popüler taksi yolculuk hizmeti mobil uygulamaları karşılaştırılmıştır. Bu sayede çalışma, farklı işlem ve işlev kombinasyonlarıyla geliştirilecek yeni mobil uygulamalar için alternatif taksi yolculuk hizmet süreç modellerinin tasarlanmasında ya da var olanların yeni sürümlerinin geliştirilmesinde başvurulabilecek basit bir kılavuz niteliği kazanmıştır. Son olarak, hali hazırda kullanılanlara ek olarak yolcunun yolculuğuna hakimiyetini artıracak yeni işlevlere sahip (örneğin; yolcunun yolculuğun herhangi bir anında yolculuk değişkenlerine ve bu değişkenlere bağlı olarak değişen çıktılarına göre rota değiştirebilmesini sağlamak) yeni bir taksi yolculuk hizmet modeli tasarlanmıştır.

$\mathrm{Bu}$ makalenin, ikinci bölümünde mobil uygulamaların benimsediği, bir süreç olarak yolculuk hizmet modeli incelenmiş ve mevcut mobil uygulamalardan bazıları benimsedikleri modele dayalı olarak sınıflandırılmıştır. Üçüncü bölümde, yolcunun mutlak hakimiyeti stratejisini güçlendirecek yeni hizmet süreç modeli önerilmiştir. Son olarak, modelin geliştirmeye elverişliliği ve kullanılabilirliğine yönelik öngörüler tartışılmıştır. 


\section{Materyal ve Metot}

\subsection{Mevcut Yolculuk Modelleri ve Mobil Uygulamalar}

Yolcunun yolculuk öncesinde ve sırasında yolculuğa hakimiyetini sağlamak ya da artırmak stratejisi üzerine farklı işlev ve hizmetleri bir araya getiren alternatif süreç modelleri tasarlanmış ve teknolojiden faydalanarak bunlara dayalı birçok mobil uygulamalar geliştirilmiştir [12]. Bu stratejilerden en çok faydalanılanlardan biri yolcunun, yolculuk öncesinde ve sırasında yolculuğuna aktif ve mutlak hakimiyetini sağlamak ya da artırmaktır. Yolcunun yolculuğa hakimiyetini sağlamak ya da artırmak amacıyla yolculuk bir süreç olarak ele alınmalı ve doğru modellenmelidir.

$\mathrm{Bu}$ çalışmada öncelikle, mevcut bazı mobil uygulamaların söz konusu strateji kapsamında taksi yolculuk hizmet süreç modelleri incelenmiş ve genel olarak benimsenen jenerik modelin yanında, farklı yolculuk hizmet süreç modelleri ve tüm modellerle ilişkili işlem ve işlevler araştırılmış ve ortaya çıkarılmıştır.

\subsection{Uygulamaların Belirlenmesi ve Arama}

İnceleme için Google Play Store uygulama mağazasında taksi yolculuğuna ilişkin mobil uygulamaları bulmak için arama yapılmıştır. Google Play Store, Android İşletim Sistemi'ni kullanan akıllı telefonların uygulama mağazasıdır. $\mathrm{Bu}$ nedenle, Google Play Store'un uygulaması Android İşletim Sistemi kullanan akıllı telefonlarda yüklü olarak gelmektedir. İnceleme yapılacak mobil uygulamaların kaynağı olarak Google Play Store'un seçilmesinin arkasındaki neden, Google'ın mobil cihazlar için geliştirdiği Android İşletim Sistemi'nin ülkemizdeki pazar payıdır. Ülkemizde Android İşletim Sistemi'nin pazar payı Ocak 2019'da \%82,02 iken Ağustos 2020 'de ise \%84,56'ya yükselmiştir [13]. Bu durumu yansıtan istatistikler Tablo 2'de görülmektedir.

\section{Tablo 2. Mobil Aygıt İşletim Sistemlerinin Türkiye'deki Pazar Paylarl}

Google Play Store'da yapılan arama sonuçlarında bulunan mobil uygulamalardan 14 tanesi belli kriterlere göre daha detaylı incelemeye alınmıştır (Uber, Careem, Bolt, Cabify, Free Now Taxi, Taxi Fare\&Meter, Taxi Fare Calculator, TaxiMetTaximeter, iTaksi, BiTaksi, EnTaksi, Tezz Taksi, istTaksi, OTaksi). Adı geçen uygulamaların bu çalışmada yer almalarının arkasındaki kriterlerden ilki çalışma ölçekleridir. Bu alandaki uygulamalar öncelikle kullanıldıkları ölçeğe göre yerel, ulusal ve uluslararası olarak sınıflandırılmışlardır. Bir başka neden ise, söz konusu sınıflandırmaya göre popülerlikleri, diğer bir ifadeyle, Google Play Store'da indirme sayıları dikkate alındığında, çalışma ölçeği sınıflandırmasına göre her bir sınıfta öne çıkan taksi yolculuğu uygulamaları arasında olmalarıdır. Buna göre; uluslararası çapta faaliyet gösteren uygulamalar, Google Play Store'un uygulama indirilme sayısı ölçeğini dikkate aldığımızda Uber 500 milyon+ (500 milyon $1-1$ milyar aras1), Bolt 10 milyon+ (10 milyon 1 - 50 milyon arasi), Careem 10 milyon+ (10 milyon 1 - 50 milyon aras1), Free Now - MyTaxi 10 milyon+ ve Cabify 10 milyon+ (10 milyon $1-50$ milyon arası) indirme ile ilk 10 'da yer almaktadırlar. Uluslararası çapta faaliyet gösteren uygulamalar 10 milyon+ indirilme sayıs

\begin{tabular}{|c|c|c|c|}
\hline Tarih & Android & IOS & Diğer \\
\hline Ocak 2019 & 82,02 & 17,1 & 0,88 \\
\hline Ăgustos 2019 & 82,54 & 16,76 & 0,71 \\
\hline$\overline{\text { Ăgustos } 2020}$ & 84,56 & 15,13 & 0,31 \\
\hline
\end{tabular}

Arama yapmak için Türkçe \{“taksi", "ulaşım”\}, İngilizce \{"taxi”, "ride”, “cab”, "booking”\} anahtar sözcükleri kullanılmıştır. Aramalarda kapsamı daraltmak için “-game” (Tr. oyun) ibaresi kullanılarak anahtar sözcükleri içeren oyunların arama sonuçlarında yer almaması için uğraşılmıştır. Yapılan arama sonuçları temizlenerek taksi yolculuk hizmetine yönelik olmayan uygulamalar sonuç listesinden çıkarılmıştır. Arama sonucunda 359 farklı mobil uygulama bulunmuştur.

Söz konusu mobil uygulamaların çalışmaya dahil edilmesinin ardından, uygulamalarda yolculuğa dair işlev, işlem ve imkan tiplerini bulmak amacıyla her bir uygulama için şu işlemlerden en az üçü gerçekleştirilmiştir;

- Uygulamanın Google Play Store sayfasının incelenmesi,

- Uygulamayı indirme, yükleme ve kullanma,

- Uygulamanın Web sitesinin, uygulamanın özellikleri ile ilgili bölümlerinin incelenmesi [44- 54],

- Uygulama Web sitesinde uygulamanın ait olduğu şirket ya da geliştiricilerinin yayımladığı dokümanların (teknik raporlar, vb.) okunması [55],

- Uygulamanın farklı senaryolarda kullanılmasına yönelik sosyal medyada paylaşılmış youtube videoların izlenmesi [56-70],

- Uygulamanın ait olduğu şirket ya da geliştiriciler ile iletişime geçme

o Telefon görüşmesi yoluyla,

o E-posta yoluyla

- Uygulama hakkında yürütülen bilimsel araştırma raporlarının incelenmesi (bildiri, makale vb.) [71-72]

Bununla birlikte, mobil uygulamalarda yürütülen hizmet süreç modelleri ve bu modelleri meydana getiren işlem ve işlevlerin ortaya çıkarılması amacıyla, taksi yolculuğuna ilişkin

kriterini sağlayan toplam 16 sayıda mobil uygulama arasından seçilmişlerdir [30-32]. Ayrıca, uluslararası ölçekte kullanılan muadilleri ile karşılaştırılmak üzere ulusal ve yerel sınıfta yer alan, ülkemizde kullanılan ve popüler olan mobil uygulamalar da aynı yöntemle belirlenmiştir.

\subsection{Jenerik Model}

Çalışmaya yolculuk hizmet modeline dair detaylı inceleme ve jenerik bir model çıkarma amacıyla dahil edilen uygulamalarda birçok farklı işlev ve işlem bulunmuştur. Söz konusu işlem ve işlevler dikkate alınarak; mobil uygulamaların verdiği hizmet için, yolculuğu merkeze yerleştiren jenerik bir süreç modeli tasarlanmıştır. Bu modele göre yolculuk, yolculuk öncesi yolculuk tasarlama, yolculuk eşleştirme, taksiyi bekleme, yolculuk seyir takibi ve yolculuk sonu ve sonrası olmak üzere beş aşamalıdır. Model, Şekil 1'de görülmektedir.

Birinci aşama, yolcunun yolculuk başlangıç ve varış (hedef) noktalarını ve yolculuk tasarlamaya ilişkin diğer bilgileri (örneğin; taksi tipi) girmesinin ardından, yolculuk öncesinde 
yolculuk seyri ve sonuna ilişkin çıktılarını hesaplayarak yolcuyu yolculuk hakkında bilgilendirmeyi amaçlamaktadır. Bu nedenle "Yolculuk Tasarlama (Yolculuk Öncesi)" olarak isimlendirilmiştir. $\mathrm{Bu}$ aşamada, mobil uygulamalar yolcu için genel olarak

- Başlangıç ve varış konumlarını birleştiren bir yolculuk rotası hesaplama

- Rotayı görselleştirerek harita üzerinde sunma

- Rotada tahmini toplam yolculuk (varış) süresini hesaplama ve gösterme

- Toplam yolculuk ücretini hesaplama ve sunma gibi işlevleri ortak olarak yapmaktadır.

Birinci aşamadan ikinci aşamaya geçiş, yolcunun birinci aşamada hesaplanan yolculuk değişkenlerini (rota, tahmini varış
Dördüncü aşama ise yolcunun, yolculuk seyrini kontrol edebilmesini sağlamak üzere tasarlanmıştır. Yolcunun çağırdığı taksiye binmesiyle başlayan bu aşamada, yolcuya yolculuk durum göstergeleri (anlık konum, geçen süre, vb.) anlık olarak yansıtılır. Böylece yolcu yolculuğun gidişatını takip edebilir. Yolculuk seyir takibi (yolculuk durum takibi), yolculuk durum göstergeleri ya da takip değişkenleri olarak adlandırılabilen ve yolculukta o ana kadar geçen yolculuk süresi, tahmini kalan yolculuk süresi, anlık toplam ücret, anlık konum gibi değişkenlerle tanımlanabilir. Bu aşamayı da kapsayan hizmet süreç modelleri Tablo 2'den de izlenebildiği üzere çok çeşitlilik göstermektedir.

Beşinci ve son aşama ise, alınan yolculuk hizmetinin

süresi, vb.) görüntülemesinin ardından yolculuk yapma isteğini

değerlendirilmesi ve geleceği ile ilgili işlem ve işlevlere

\section{Şekil 1Mobil Uygulamalardaki Jenerik Hizmet Süreç Modeli ve Aşamaları}

onaylaması ile gerçekleşir. İkinci aşama olan yolculuk eşleştirmede önce, yolcunun konumunu merkez alan ve değiştirilebilir çapta bir daire içinde yer alan taksiler hesaplanarak yolcuya görüntülenir. $\mathrm{Bu}$ sayede yolcu istediği taksi ile yolculuk yapma imkanına sahip olur. Bazı uygulamalar taksilerin yolcuya mesafesi ve tahmini ulaşım süresini de hesaplayarak yolcunun bu kıstaslara göre seçeceği taksi ile yolculuk yapabilmesini sağlamaktadır.

Jenerik modelin üçüncü aşaması olan “taksiyi bekleme”ye, yolcunun seçtiği taksiyi çağırması ve taksi şoförünün çağrıyı kabul etmesi ile geçiş yapılır. Yolcu, bu aşamada çağırdığı taksinin kendisine ne kadar mesafede olduğu ve mevcut konumu gibi bilgileri anlık görüntüleyebilir. Böylece bekleme süresini istediği gibi değerlendirebilir. $\mathrm{Bu}$ aşamada, yolcu taksiyi beklerken çağrı iptal işlemi de yapabilir.

detaylı incelemeye tabi tutulmuş uygulamalar iki kritere göre iki seviyede tasnif edilmiştir, benimsedikleri modele ve kullanılma ölçeklerine göre. Bu sınıflandırmada, uygulamalar önce jenerik modeli uygulayanlar ve diğer modelleri benimseyenler olarak sınıflandırılmıştır. Jenerik modeli uygulayanlar "uluslararası ölçektekiler" ve "ulusal ve yerel ölçektekiler" olarak ikinci seviyede sınıflandırılmışlardır. Dolayısıyla, her bir aşama ve bunların işlem ve işlevleri için, birbirlerinin muadili olan uygulamaları kapsayan 3 sınıfta tablolar hazırlanmıştır. $\mathrm{Bu}$ sayede, Yurtiçi ve Yurtdışında kullanılan uygulamaların işlevsellikler açısından karşılaştırılması yapılmıştır.

\section{Bulgular}

\subsection{Mobil Uygulamalarda İşlevlere Dayalı Farklılıklar}

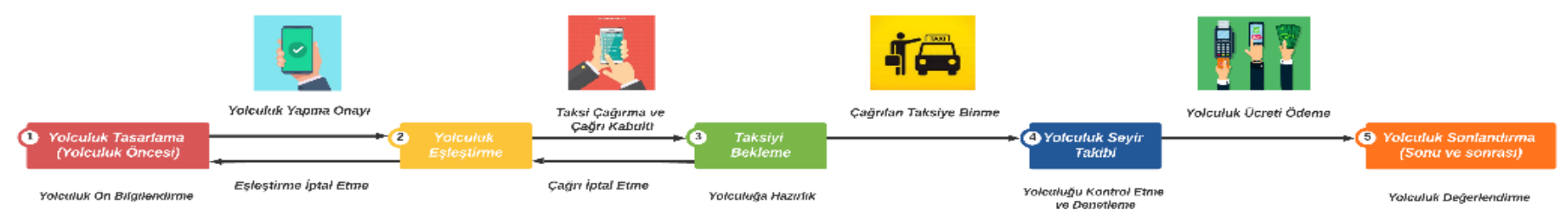

Her bir aşama için, uygulamalar için tasarlanan sınıflandırmaya göre hazırlanan ve uygulamaların sahip yöneliktir. Yolcunun aldığ1 hizmet karşılığı ücreti ödemesi ile başlar. Bu aşamada yolcu, yolculuk öncesi ve yolculuğun seyri ile ilgili değerlendirmesini yapabilir. Bununla birlikte, yolcunun gelecek yolculuklarını sonlanan yolculuğunun bileşenleriyle şekillendirmesini sağlayacak, favori rota ekleme, vb. işlev ve işlemler de bu aşamadadır.

\subsection{Tablolama ve Karşılaştırma}

Öncelikle toplanan işlev ve işlemlerin her biri, jenerik model temel alınarak uygulandıkları aşamalarla ilişkilendirilmişlerdir. $\mathrm{Bu}$ işlev ve işlemlerin hangi mobil uygulamalarda olduğunu göstermek üzere tablolama benimsenmiştir. Tablolama için,

oldukları ve olmadıkları işlev ve işlemleri gösteren tablolar aşağıdadır.

İlk 3 tablo, jenerik modelin ilk aşaması yolculuk tasarlamada bulunan işlevlerin hangi mobil uygulamalarda bulunduğunu göstermektedir. Bu üç tablo incelendiğinde; ilk aşamada uluslararası ölçekte kullanılan uygulamalarda bulunan fakat ulusal ve yerel çaplı uygulamalarda bulunmayan beş işlev ya da imkân (2.,4., 5.,9. ve 11.) dikkat çekmektedir. Örneğin; ikinci sırada listelenen "Başlangıç ve Bitiş Adreslerine Göre Alternatif Yolculuk Rotalarını Hesaplamak ve Haritada Gösterme" işlevi ulusal ve yerel uygulamalarda bulunmamaktadır.

$\mathrm{Bu}$ üç tabloda, yolculuk tasarlama aşamasına dair dikkat çeken bir başka nokta ise "Başlangıç ve Bitiş Adreslerine Göre
Alternatif Yolculuk Rotalarını Hesaplamak ve Haritada Göstermek" işlevine ilişkindir. Bu işlev, ticari model olarak da isimlendirilebilecek jenerik modeli benimseyen ne uluslararası 
ne ulusal ve yerel uygulamalarda bulunmaktadır. Söz konusu işlevi, 1., 4. ve 5. Aşama kombinasyonunu yürüten bir uygulama olan Taxi Fare \& Meter adlı uygulama sağlamaktadır.

Dikkat çeken bir başka nokta ise; yolcunun yolculuğunu tasarlarken rota üzerindeki genel trafik durumunu haritada görebilmesini (rota üzerindeki trafik akış ve sıkışıklıklarını göstermek) yalnızca Careem adındaki ticari model üzerine geliştirilmiş uluslararası uygulamanın sağlayabilmesidir.

Tablo 4a ve 4b, birinci aşamadan ikinciye geçiş ve ikinci aşamaya dair işlev ve imkânları uygulamalara göre göstermektedir. Birinci aşamadan ikinciye geçişte, uluslararası çapta mobil uygulamalar ile ulusal ve yerel çapta mobil uygulamalar arasında dikkat çeken bir işlev farklılığı gözlenmemiştir. Fakat ikinci aşamaya dair üç imkân (bebek koltuklu taksi talep edebilme, evcil hayvan ile yolculuk edebilme ve engelli yolcuya uygun taksi talep edebilme) yönelik bir başka bulgu dikkat çekmektedir; ulusal ve yerel çapta kullanılan bir mobil uygulama, çalışmadaki tüm uygulamalar arasında bu üç imkanı da sağlayan tek uygulamadır. Ayrıca, bu üç imkandan en azından birini sunan uluslararası çaplı mobil uygulama var iken ulusal çapta ise adı geçen üç imkanı sağlayan mobil uygulama haricinde mobil uygulama yoktur.

İkinci aşamada dikkat çeken farklılıklardan biri de yolculuk etmeyi tercih edeceği taksi araç gövde tipini seçebilme (sedan, station wagon, vb.) imkânı ile ilişkilidir. Bu imkân, uluslararası çapta faaliyet gösteren mobil uygulamalarda bulunurken, ulusal ve yerel çapta faaliyet gösteren mobil uygulamaların hiçbirinde bulunmamaktadır. Yolculuğu başka yolcularla yapıp ücreti paylaşabilme işlevi de benzer şekilde hiçbir ulusal ve yerel çapta faaliyet gösteren mobil uygulamada bulunmazken, yalnız bir uluslararası çapta çalışan mobil uygulamada bulunmaktadır.

Bir sonraki aşama olan Taksi Bekleme'deki ve bu aşamaya geçişteki işlev ve imkânlar Tablo 5a ve Tablo 5b'de görülmektedir. Buna göre, uluslararası çaptaki mobil uygulamalar ile ulusal ve yerel çaptaki mobil uygulamalar arasında yalnız bir fark belirgin şekilde dikkat çekmektedir. Uluslararası çaptaki mobil uygulamalarda, resmi taksi siciline sahip olanlar haricindeki araç sahiplerinin de kayıt olarak ulaşım hizmeti verebilecekleri bir filo yaratılmıştır. Ulusal ve yerel çaptaki mobil uygulamalarda ise yalnız hali hazırda resmi taksi siciline sahip taksilerden meydana gelen bir filo ile ulaşım hizmeti verilebilmektedir.

Dördüncü aşama olan Yolculuk Seyir Takibi'nde ve ona geçişteki işlev ve imkânlar, her iki grup mobil uygulama için (uluslararası çapta çalışanlar ve ulusal ve yerel çapta çalışanlar) Tablo 6a ve Tablo 6b'de listelenmiştir. Her iki gruptaki mobil uygulamalarda da Rotadaki Anlık Konumu Hesaplamak ve Göstermek işlevinin bulunduğu görülmüştür. $\mathrm{Bu}$ işlev yolcunun yolculuğuna hakimiyeti açısından önem arz etmektedir. Diğer taraftan, bazı işlevlerin her iki grup mobil uygulamada da bulunamamıştır. Bunlar;

1. Rotadaki Anlık Toplam Yolculuk Süresini Hesaplamak

2. Rotadaki Anlık Toplam Kalan Yolculuk Süresini Hesaplamak

3. Rotadaki Anlık Toplam Alınan Mesafeyi Hesaplamak

4. Rotadaki Anlık Toplam Kalan Mesafeyi Hesaplamak

5. Rotadaki Anlık Trafik Durumunu Göstermek- Kalan

Kisimda Trafik Durumu

6. Anlık Toplam Ücret Hesaplamak
$\mathrm{Bu}$ işlevler yolculuk seyir takibini kolaylaştırabilecek ve yolcuya yolculuğu hakkında karar-destek sağlayabilecek yolculuk değişkenleri ile ilişkilidir. Listelenen işlevlerin ilişkili olduğu değişkenlerden rotadaki anlık toplam yolculuk süresi, rotadaki anlık toplam kalan mesafe, anlık toplam ücret ve rota üzerinde anlık trafik durumu (mevcut konumdan belli bir mesafeye kadar) gibi yolculuk seyir değişkenleri bunlar arasında sayılabilir. Bununla birlikte, rota değiştirme işlevi de çalışma dahilindeki mobil uygulamalarda bulunamayanlardır. Rota değiştirme işlevi, yolcunun özellikle bazı durumlarda (mevcut konuma gelene kadar geçen toplam sürenin yolcunun gecikebileceğini göstermesi, gelen bir haber ile varış noktasının değişmesi, vb.) başvurmak isteyebileceği bir çözüm olabilir. $\mathrm{Bu}$ bakımdan, yukarıda adı geçen yolculuk seyir değişkenleri, rota değiştirme kararı verirken yolcunun proaktif şekilde faydalanabileceği göstergelerdir. Dolayısıyla, bu işlevler birbiriyle de doğrudan ilişkilendirilebilir.

Rota değiştirme işlevi ile doğrudan ilişkili olarak yolcunun faydalanabileceği bir başka anlık yolculuk göstergesi ise rota üzerindeki anlık trafik durumudur. Çalışma dahilindeki mobil uygulamalarda, rota üzerinde anlık trafik durumunu yolculuk esnasında (4.aşamada) gösterme işlevi de bulunamamıştır. Mobil uygulamaların, anlık trafik durumunu yolculuk esnasında yolcuya gösterebilmesi, yolcunun rota değiştirme kararında etkili olabilir.

Son aşama olan Yolculuk Sonlandirma'da ve bu aşamaya geçişte, genel itibariyle uluslararası çapta ve yerel ve ulusal çapta faaliyet gösteren mobil uygulamalar arasında anlamlı işlevsel bir farklılık göze çarpmamıştır. Örneğin; aşama geçişinde, "alınan yolculuk hizmet ücreti ödeme" imkânları açısından hiçbir farklılık yoktur. Aşama dahilinde ise "alınan hizmeti değerlendirme", "son yolculuk edilen adresi favori adres olarak ekleme", "geçmiş yolculukları görüntüleme" ve "şoför ile iletişime geçebilme" gibi işlevler her iki kategorideki mobil uygulamalarda da bulunmaktadır. Diğer taraftan, "geçmiş yolculuk takip dökümü çıkarma" imkânı yalnızca uluslararası çapta hizmet veren uygulamalarda bulunmaktadır. $\mathrm{Bu}$ işlev, yolculuk seyir göstergelerinin lokal olarak (akıllı telefona) ya da uzak makineye kayıt edilmesini sağlar. Elbette her iki seçenek de belli bir veri saklama kapasitesi gerektirmektedir. $\mathrm{Bu}$ işlev, yolcunun karşılaşabileceği farklı durumlarda fayda sağlayabilir. Örneğin; yolculuğunun rotası ve duraklarına varışlarını, yolculuğunun ardından bildirmesi gereken üçüncü taraflar için (özellikle ücret geri ödeme ile ilgili olarak) önem arz edebilir.

\subsection{Mobil Uygulamalarda Benimsenen Alternatif Hizmet Süreç Modelleri}

$\mathrm{Bu}$ çalışmada, yukarıda sunulan beş aşamalı jenerik yolculuk hizmet süreç modeli, yolculuğu bütünsel bir yaklaşım ile ele almaktadır. Fakat mobil uygulamalar, bu süreç modelinin aşamalarının farklı kombinasyonlarından türevlendirilen süreç modelleri üzerine geliştirilmişlerdir. Daha açık bir ifadeyle, mobil uygulamalardan bazıları, jenerik süreç modelinin yalnız bir ya da birkaç aşaması üzerine tasarlanan bir modele dayalı olarak geliştirilmişken, bazıları tüm aşamalarını kapsayan bir süreç modelini benimsemiş ve bu model üzerine geliştirilmiştir. $\mathrm{Bu}$ bakımdan örneğin; Taxi Fare Calculator isimli mobil uygulama yalnız birinci aşamaya dair işlem ve işlevler barındıran ve yalnız birinci aşamayı temel alan süreç modelini 
gerçekleştiren bir uygulamadır. Yalnız bir aşamayı süreç tasarımına dahil eden bir başka mobil uygulama ise dördüncü aşama olan yolculuk seyir takibine dair işlem ve işlevlere sahip TAXImet'dir. TAXImet, yolcunun taksimetre ölçüm değişkenleri için gireceği değerlere istinaden, GPS'den de faydalanarak yolculuğu sırasında taksimetre gibi anlık ücreti hesaplayarak bilgilendirmektedir. Jenerik modelden farklı bir aşamalar kombinasyonuna dayalı modeli gerçekleştiren mobil uygulama ise Taxi Fare\&Meter'dır. Bu uygulama, jenerik modeldeki üç aşamayı (1., 4. ve 5. aşamalar) benimseyen bir modele dayalı olarak geliştirilmiş ve çalışmaktadır. Bu çalışmada detaylı incelemeye tabi tutulan diğer mobil uygulamaların hepsi jenerik modele göre çalışmaktadırlar.

Fakat aynı yolculuk hizmet süreç modelini (örneğin; jenerik modeli) benimseyen uygulamalar dahi hizmeti meydana getiren birbirinden farklı işlem ve işlevler ile donatılmışlardır. Hâttâ ortak olan işlevlerde dahi bazı farklı yaklaşım, yöntem ve algoritmalar dikkat çekmektedir. Örneğin; Uber dinamik ücretlendirme adını verdiği ve taksi çağrı istek saati, yolculuk rotası, yolculuk mesafesi, yolculuk süresi ve yolcu-şoför arztalep oranı gibi değişken maliyet hesabı yapan özgün bir

\section{Yeni Taksi Yolculuğu Modeli}

Mevcut model ve mobil uygulamaların ana hedefi, yolcunun, yolculuk hakimiyetini sağlayabilmek ve memnuniyetini artırabilmektir. Ancak yolculuk dinamik bir süreçtir ve yolculuğun bütünü için tutarlı ve sürdürülebilir bir hizmet, yolculuk boyunca değişebilen şart ve istekler ile değişen yolculuğa adaptasyon gerektirir. $\mathrm{Bu}$ da beraberinde sistemin yenilenmesini gerektirmektedir. Zira elde edilen bulgulara dayanarak, yolcunun yolculuk hâkimiyetini ve memnuniyetini zayıflatabilecek iki durum keşfedilmiştir:

1. Yolculuğun planlanmasıyla hesaplanan yolculuk göstergeleri, yolculuk sırasında karşılaşılan gecikmelerle (örneğin trafik yoğunluğuyla) değişebilir. Dolayısıyla başlangıçtaki hesaplamalar, gerçek sonuçlardan uzak değerler haline gelebilir.

2. Yolcu yolculuğun herhangi bir anında farklı bir varış konumuna gitmek isteyebilir. $\mathrm{Bu}$ durumda, yolcu ve şoför yeni bir sezgisel rota oluşturmalıdır. Yolculuğun sezgisel olarak sürdürülmesi, incelenen uygulamaların varoluşsal güdülerine aykırıdır ve kullanılmalarıyla ilgili faydayı

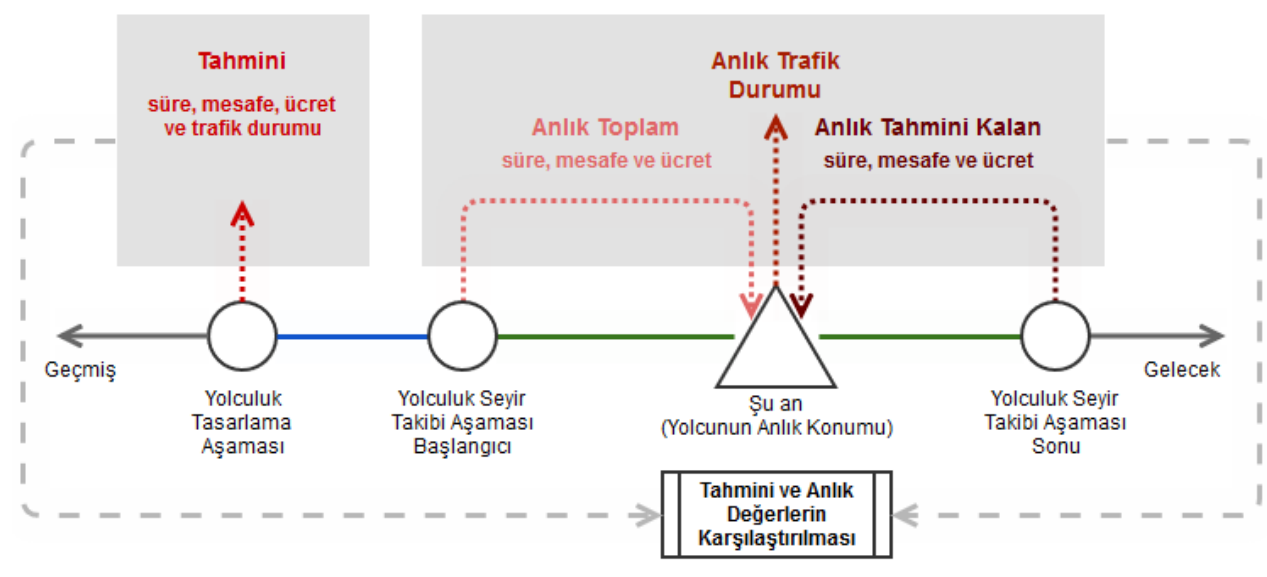

Şekil 2. Yolculuk Göstergelerin Hesaplandı̆̆ı Zaman Nokta ve Aralıkları

algoritma kullanarak ücreti hesaplamaktadır [33]. Bununla birlikte, hesaplanan ücret yolcuya o yolculuk için belli bir süre geçerli olacak şekilde sunulmaktadır. Yolcunun kabul etmesi ve yolculuğun daha fazlaya mal olması halinde ise yolcu hesaplanan ve sunulan ücretten fazlasını ödemez. BiTaksi adlı mobil uygulama ise yolculuk mesafesi ve taksimetre ölçütlerinden tarife tipi (gündüz ve gece), açılış ücreti, birim mesafe ücreti ve benzeri değişkenleri kullanan bir algoritma ile tahmini toplam yolculuk ücreti hesaplamaktadır. Bu yöntemi OTaksi mobil uygulaması da benimsemiştir. Yolcunun OTaksi mobil uygulamasında yolculuğu için hesaplanan tahmini ücreti gördükten sonra taksi çağırması ve taksi ile yolculuk etmesi üzerine ise taksinin taksimetresinin yolculuk için yaptığı ölçüm sonunda ortaya çıkan ücret uygulanmaktadır. OTaksi mobil uygulaması geliştiricileri, yine de müşterilerini mağdur etmemek için, Uber'in ücretlendirmesine benzer şekilde, birinci aşamada hesaplanan tahmini toplam yolculuk ücretinin yolcuya ücret olarak yansıtıldığını ve varsa, taksimetrenin hesapladığı ücret farkını taksiciye ödediklerini yaptığımız görüşmelerde belirtmişlerdir.

Mobil uygulamalardaki bu tip algoritmik farklılıklar tablolarda görülmektedir. büyük ölçüde azaltabilir.

İlgili problemler yolculuk esnasında gerçekleşir. Dolayısıyla, "Yolculuk Seyir Takibi (4.)" aşaması için iki yeni imkân öneriyoruz: yolculuk sırasında, yolculuk göstergelerinin planlamadaki (yolculuk tasarım aşamasındaki) değerleri ile yolculuk sırasındaki (yolculuk seyir takibi aşamasındaki) anlık değerlerinin karşılaştırılması ve rotanın değiştirilebilmesi.

Yolcu, yolculuk tasarlama aşamasında ve yolculuk sırasında hesaplanan yolculuk gösterge değerlerini karşılaştırarak, yolculuk yapmak için seçilen rotanın (örneğin daha kısa yolculuk süresine sahip olanın), beklenilen faydayı (istenilen bir zamanda varış) sağlayabilme becerisini takip edebilir. Bu aynı zamanda, verilen hizmette tutarlılığın kontrol edilmesine de katkı sağlar. $\mathrm{Bu}$ ilkelerden ve elde edilen bulgulardan hareketle, mevcut mobil uygulamalarda eksik olduğu tespit edilen ve eklenmesi önerilen işlevler aşağıdaki gibidir:

- Anlık toplam yolculuk süresini hesaplamak

- Anlık tahmini kalan yolculuk süresini hesaplamak

- Anlık toplam alınan mesafeyi hesaplamak

- Anlık kalan mesafeyi hesaplamak

- Anlık toplam ücreti hesaplamak

- Anlık tahmini kalan ücreti hesaplamak 
- Anlık trafik durumunu göstermek

Yukarıda listelenen göstergelerle yeni işlevler, "Yolculuk Tasarlama (1.)" aşamasında yapılan işlevlerle eşdeğerdir. Buna göre yeni işlevlerle, yolculuğun tamamlanması için kalan rota parçasının yolculuk göstergeleri hesaplanır. Hesaplanan değerler, yolculuğun başlangıcından mevcut konuma (zamana) kadar ölçülmüş eş değerleriyle (örneğin toplam yolculuk süresi ve kalan tahmini yolculuk süresi) toplanır. Elde edilen son değerler, mevcut rota için hesaplanmış anlık yolculuk göstergeleridir ve aşağıdaki gibi 3 yeni işlevle gösterilir:

- Yolculuğun tamamı için anlık tahmini yolculuk süresinin hesaplanması

- Yolculuğun tamamı için anlık tahmini yolculuk ücretinin hesaplanması

- Yolculuğun tamamı için anlık yolculuk mesafesinin hesaplanmas1

Böylece planlama aşamasındaki değerlere göre anlık yolculuk göstergelerinin değişim miktarları hesaplanabilir. Şekil 2, bir zaman şeridinde planlanan ve anlık yolculuk göstergelerinin hesaplandığı zaman noktalarını gösterir. Buna göre;

- "Tahmini" olarak gösterilen planlama aşamasındaki yolculuk göstergeleri bir kez hesaplanır. Dolayısıyla yolculuk sonuna kadar değişmeyen sabit değerlerdir.

- “Anlık Toplam", “Anlık Tahmini Kalan" ve "Anlık Trafik Durumu" olarak gösterilen değişkenler, yolculuk sonuna kadar, belirli aralıklarla (örneğin; her 5 saniyede bir) hesaplanır. Dolayısıyla sürekli olarak değişebilecek dinamik değerlerdir.

- "Tahmini ve Anlık Değerlerin Karşılaştırılması" işlemi, sabit ve dinamik değerlerin zaman içerisindeki değişimini hesaplar.

Rotanın değiştirilebilme imkânı, yolculuk esnasındaki mevcut konumdan gidilmek istenen varış konumlarına göre rotaların yeniden hesaplanmasını amaçlar. Böylece yolculuk tekrar tasarlanarak verilen hizmetin sürdürülebilirliği sağlanabilir. Genel olarak, yolculuğun tekrar tasarlanmasının iki nedeni olabilir. Birincisinde, yolcunun kişisel planındaki değişiklikler etkilidir. Örneğin yolcu, ebeveynlerinden aldığı bir haber doğrultusunda yanlarına gidebilmek için rotasını değiştirmek isteyebilir. İkincisinde, planlanmış ve anlık yolculuk göstergelerinin arasındaki değişim etkilidir. Örneğin "Yolculuk Tasarlama (1.)" aşamasında 35 dakika süreceği hesaplanmış bir rotadaki 10 dakikalık bir yolculuk sonrasında, geri kalan rotanın 45 dakika (35-10=25 olarak 25 dakika kalması gerekirken) zaman alacağı hesaplanmış olsun. $\mathrm{Bu}$ durumda yolcu, yolculuğun daha kısa sürede tamamlanabileceği bir rota seçimi yapmak isteyebilir.

$\mathrm{Bu}$ yönüyle rota değiştirebilme imkânı, yolculuk göstergelerinin karşılaştırılması işlevlerinden beslenir. Başka bir ifadeyle rotanın değiştirilmesi, seçilen rotanın beklenilen faydayı karşılayabilme miktarıyla ilgilidir. Dolayısıyla planlanan ve anlık yolculuk göstergelerinin karşılaştırılması işlevleri, yolcunun rota değiştirme işlevlerini gerçekleştirmesinde bir karar-destek mekanizması sağlamaktadır.

Önerilen imkanlar, mevcut mobil uygulamalar tarafindan kullanılan jenerik modeli değiştirmektedir. Buna göre, yeni hizmet modeli yönlü bir çizge halinde Şekil 3'deki gibi tasarlanmıştır. İlgili model, jenerik modeldeki yapıya ek olarak üç durum geçişini kapsar: "Yolculuk seyir göstergelerini kontrol etme", "Rota değiştirme istemi" ve "Şoföre yolculuğun yeni rotasını bildirme". Eklenen geçişler şekildeki kırmızı renkli oklarla gösterilmiştir.

Birden fazla aşamayı kapsayan süreç modellerinde, bir aşamadan diğerine geçiş önemli bir tasarım ve uygulama detayıdır. Durumlar ya da aşamalar arası geçiş, belli işlev ya da işlemin gerçekleştirilmesine ya da olaya bağlı olarak tasarlanır. Söz konusu işlem ya da işlev, mevcut aşamayı sonlandıran ve sonraki aşamayı başlatandır. Bu nedenle, geçişler tasarımın ana bileşenlerindendir ve modelin doğruluğunda etkin ana unsurlardir.

"Yolculuk seyir göstergelerini kontrol etme" işlemi, belirli bir sürede tekrarlanarak, "Yolculuk Seyir Takibi" aşamasına ait işlevlerin yürütülmesini sağlamaktadır. Böylece yolculuk göstergelerinin değerleri, yolculuğun sonuna kadar periyodik olarak hesaplanabilir ve "Yolculuk Tasarlama (1.)" aşamasında hesaplanmış değerlerle karşılaştırılabilir. 


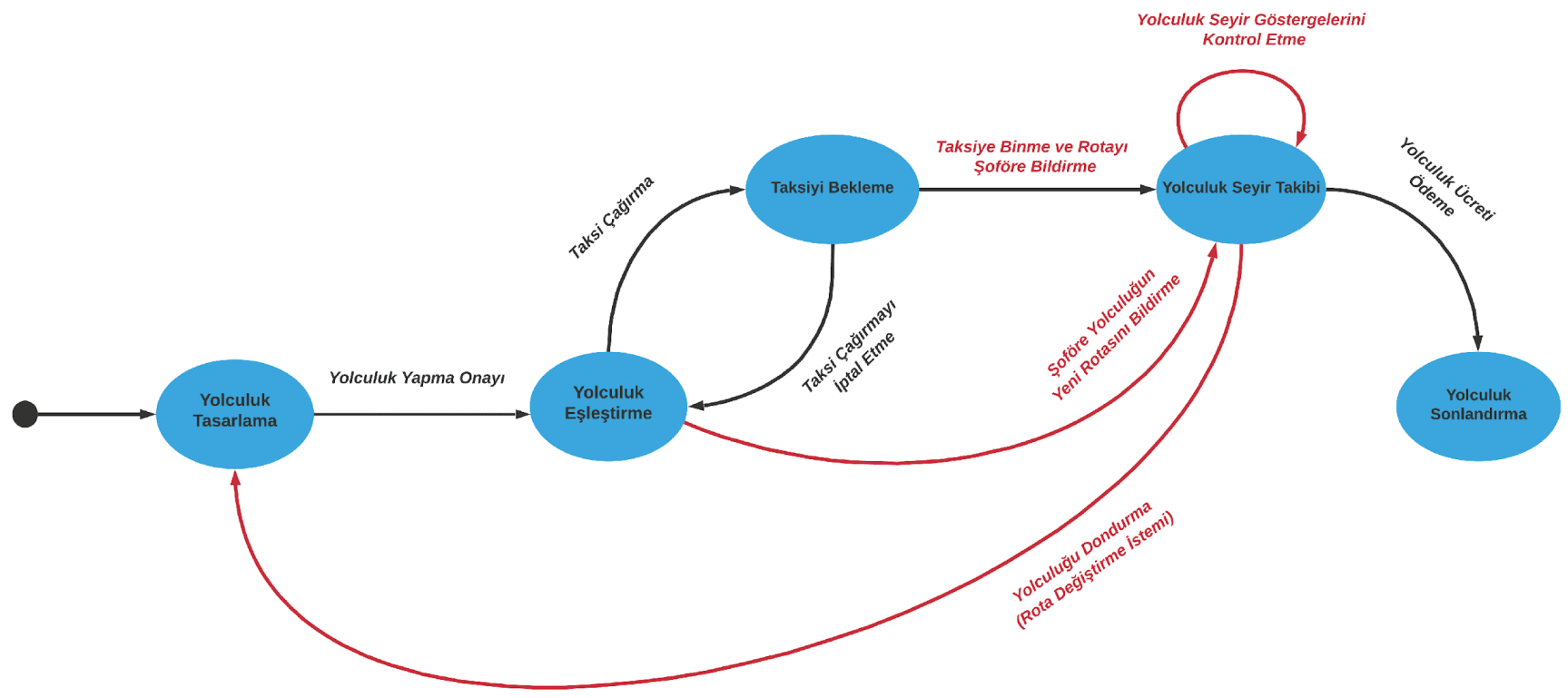

Şekil 3. Mobil Uygulamalar İçin Önerilen Yolculuk Hizmet Süreç Modeli

" Rota değiştirme istemi" ve "Şoföre yolculuğun yeni rotasını bildirme" işlemleri, rotanın değiştirilebilmesini sağlamaktadır. Rotanın değiştirilmesi, model durumları arasında geçiş sağlayacak potansiyel bir imkândır. Buna göre, "Rota değiştirme istemi" kullanılarak "Yolculuk Tasarlama (1.)" aşamasına geri gidilir. Böylece yolcunun anlık konumuna ve seçebileceği eski/yeni varış konumlarına göre alternatif rotalar tekrar hesaplanır. Yolcu, alternatif rotalardan birini seçebilir ya da mevcut rotasında yolculuğuna devam etmeyi seçebilir. Yeni bir rota seçmesi halinde, "Şoföre yolculuğun yeni rotasını bildirme" işlemi, "Taksi Bekleme (3.)" aşamasına geçme gerekliliğini kaldırır. Böylece tercih edilen yeni rota, kullanılmakta olan taksinin şoförüne iletilir.

Ayrıca "Şoföre yolculuğun yeni rotasını bildirme" işleminin sağladığı başka bir yenilik daha bulunmaktadır. Varsayımsal olarak yolcu, tasarlanan modele dayanan bir mobil uygulamayı, bir taksiye bindikten sonra başlatsın. Bu senaryo için de hâlihazırda kullanılabilecek bir taksi mevcuttur. Dolayısıyla "Taksi Bekleme (3.)" aşamasına geçme gerekliliği kaldırılmıştır. $\mathrm{Bu}$ modelin uygulanmasındaki temel bağımlılık, yolculuk sırasında anlık konum ve anlık konumdan varış noktasına kadar olan trafik durumu bilgilerinin hesaplanabilmesidir. Bu iki bilgi, yolculuk sırasında (yolculuk seyir aşamasında) yolculuk göstergelerinin tahmini değer hesaplamalarının doğruluğunda, dolayısıyla, yolculuk göstergelerinin başlangıç değerleri ile anlık tahmini değerlerinin karşılaştırılmasının doğrulunda etkilidir.

\section{Sonuç}

$\mathrm{Bu}$ çalışmada, taksi yolculuğuna ilişkin geliştirilmiş mobil uygulamalar incelenmiştir. $\mathrm{Bu}$ inceleme, yolcunun taksi yolculuğuna hakimiyet ve kontrol stratejisi kapsamında yapılmıştır. Popüler uygulama marketi Google Play Store'da bahsi geçen tipteki mobil uygulamaların, söz konusu strateji kapsamında işlem, işlev ve özellikleri ortaya çıkarılmıştır. Aynı zamanda, söz konusu mobil uygulamaların işlev, işlem ve özellikleri de dikkate alınarak benimsedikleri yolculuk hizmet süreç modelleri ya da desenleri gösterilmiştir. Bu sayede, söz e-ISSN: 2148-2683 konusu mobil uygulamalar bu modellere göre sınıflandırılmıştır. Böylece yeni süreç modellerinin tasarlanmasında ve bu modellere dayalı uygulamaların geliştirilmesinde kullanılabilecek basit bir kılavuz ortaya çıkmıştır. Son olarak, Google Play Store'da taksi yolculuğu mobil uygulamalarında bulunmayan işlev, işlem ve özellikler keşfedilmiş ve bunları barındıran, yolcunun taksi yolculuğuna hakimiyet ve kontrolünü artırabilecek alternatif bir süreç modeli tasarlanmıştır.

$\mathrm{Bu}$ yeni süreç modeli, uygulamaların yolculuk esnasında yolcunun yolculuğunu proaktif şekilde yönetebilmesi ve yönlendirebilmesi amacıyla, yolculuğunu tasarlarken yapılan ölçümlerde yolculuk göstergelerinin tahmini değerleri ile yolculuk sırasında periyodik anlık hesaplamalar sonunda ortaya çıkan değerlerini karşılaştırabilme imkanı sunar. Dördüncü aşama olan Yolculuk Seyir Takibi'nde, mobil uygulamaların yolculuk göstergelerini denetlemesine dayalı tasarlanmış döngüsellik ile mobil uygulamalar, yolcuya anlık bildirimler yaparak yolculuk sirasında yolculuğunun seyrini değiştirmesinde, örneğin; rota değiştirmesinde, karar-destek sağlayabilir.

Modelde yapılan değişikliğin getirdiği işlevsellik her ne kadar yolcunun mutlak kontrolünü artırma potansiyeline sahip olsa da pratikte karşılaşılabilir sorunların başında kullanılabilirlik gelmektedir. Kullanıcıların bir uygulama arayüzü ile etkileşimleri sırasında, arayüzü kullanmayı öğrenme çabaları asıl amaçları ve hedeflerinin yerini almamalıdır. Söz konusu işlevlerle güçlendirilerek geliştirilmiş bir uygulamayı kullanırken yolcunun ilgili uygulama arayüzünü kullanmayı öğrenmeye çabalaması sırasında yolculuk yolcu açısından kaosa dönüşmemelidir. $\mathrm{Bu}$ tip kullanıcı deneyimlerinin, kullanıcı kabulünü olumsuz etkilediği bilinmektedir. $\mathrm{Bu}$ nedenle, ek işlevler için doğru arayüz tasarlanması ve geliştirilen uygulama arayüzünün farklı senaryolarla, farklı karakterde kullanıcılar için test edilerek özellikle rota değişikliği tamamlama sürelerinin ölçülmesi bir gerekliliktir.

Yolculuk sırasında rota değiştirme işlevinin mevcut bazı uygulamalarda tasarıma dahil edilmeme nedeni yolculuk 
rezervasyonu yapma işlevi olabilir. Buna göre; yolculuk sırasında rota değiştirme sonucu gerçekleşecek yolculuk, toplam yolculuk süresini uzatabileceğinden, taksi şoförünün, belli bir saatte yapılması tasarlanmış ve rezervasyonu yapılmış bir yolculuğa yetişememesine neden olabilir. $\mathrm{Bu}$ soruna yönelik basit bir algoritmik çözüm olarak yolcuya yolculuk eşleştirme aşamasında, yolculuk sırasında rota değiştirebileceği ve belli bir süre dahilinde rezervasyonu olmayan taksiler gösterilebilir.

Bununla birlikte, rota değiştirme işlevi belli miktarda zaman gerektirir. Değiştirme işleminin gerçekleştirildiği süre, yolcu açısından bir maliyet getirmektedir. $\mathrm{Bu}$ maliyet iki boyutludur. Bir taraftan taksinin bekleme süresini artırırken, aynı zamanda zaman-kritik yolculuklar açısından da yolcuya varış noktasına ulaşmasında belli miktarda zaman kaybettirebilir.

Rotanın değiştirilmesi, verilen örnekler doğrultusunda yolcu tarafından yapılabilecek önemli bir işlemdir. Bununla birlikte, geliştirilen bir uygulamanın bu sürece etkin bir şekilde katılması sağlanabilir. Bu katılım, anlık ve yolculuk öncesinde hesaplanan yolculuk göstergeleri arasında anlamlı bir farkın olması sonucunda, yolcuya uyarı verilmesiyle ilgilidir. $\mathrm{Bu}$ uyarı, yolculuk öncesinde ölçüt olarak seçilen her bir yolculuk göstergesi için bir eşik ya da tavan değer belirlenmesini gerektirir. Örneğin; yolcunun yolculuk etmek için seçtiği bir rotanın tahmini yolculuk ücreti $50 \mathrm{TL}$ olarak hesaplansın. Bu ücret miktarı için yolcu en fazla \%10'luk bir artış eşiği tanımlamış olsun. Eğer yolculuğun herhangi bir anında, yolculuğun sonunda ödenmesi gereken tahmini ücretin $55 \mathrm{TL}$ (50 TL'ye ek olarak \%10'luk bir artışın olmasında) üzerinde olması tahmin ediliyor ise, yolcu bilgilendirilebilir. $\mathrm{Bu}$ bilgilendirme iki parçaya ayrılarak; aşılan yolculuk değişkeni hakkındaki bir açıklamayı ve seçilebilecek alternatif rotaları kapsayabilir. Böylece yolcunun sürekli anlık yolculuk değişkenlerine bakma gereksinimi kaldırılabilir ve yeni rota hesaplanması için daha az kullanıcı arayüzü etkileşiminde bulunması sağlanabilir.

$\mathrm{Bu}$ çalışmada Google Play Store'da yer alan taksi yolculuk hizmeti mobil uygulamaları dikkate alındıysa da ülkemizde \%15.13'lük bir payla ikinci sırada bulunan iOS platformu da dahil edilerek çalışmanın kapsamı genişletilebilir. Yine de bilinmelidir ki bu çalışma kapsamına karşılaştırma maksadıyla dahil edilen mobil uygulamaların hepsinin iOS İşletim Sistemi kullanan akıllı telefonlarda çalışan ve kullanılabilir sürümleri vardır ve iOS İşletim Sistemi'nin uygulama mağazası olan AppStore'dan indirilebilir.

Uluslararası alandaki mobil taksi uygulamalarına dayalı taksi ulaşım sektörünü, ülkemizdeki mobil taksi uygulamalarına dayalı taksi ulaşım sektörü ile karşılaştırdığımızda, özellikle yolculara sağlanan işlevsellik ve imkanlar açısından eksiklerimiz olduğu söylenebilir. Hizmet kalitesi açısından bakıldığında bu çalışmada ele alınan uluslararası çapta faaliyet yürüten mobil uygulamaların farklı işlevler ile hizmeti genişlettikleri görülebilir (örneğin; çocuk koltuğu, farklı rotaların gösterilmesi). Ülkemizde bu sektörün gelişmesine, ilgili yasal düzenlemelere yolcuyu ve elektronik ortamı dikkate alan yaklaşımların eklenmesi katkı sağlayabilir.

Ulusal ve yerel mobil uygulamalarda yalnız 1.(yolculuk tasarım) ve 4. (yolculuk seyir takibi) aşamaları temel alan mobil uygulama eksikliği göze çarpmıştır. $\mathrm{Bu}$ anlamda, bu aşamalara dair işlem ve işlevleri dikkate alan bir tasarım söz konusu çapta çalışmak üzere geliştirilebilir. Yolcuya hem yolculuğunu tasarlarken hem yolculuk seyir göstergelerini takibinde, belli başlı işlem ve işlevler seçilerek (örneğin; anlık konum ve taksimetredeki ücreti kontrol etmek üzere ücret hesaplama) geliştirilecek bir mobil uygulama bu açığı doldurabilir.

Jenerik modelin yolculuk tasarlama aşamasında tahmini toplam yolculuk süresi, tahmini toplam yolculuk ücreti ve bu çalışma kapsamında yapılan değişikliklerle 4. Aşama olan yolculuk seyir takibinde ise tahmini kalan toplam yolculuk süresi gibi göstergelerin aynı rotalarda ve günün belli zaman dilimlerinde yapılmış geçmiş yolculuklardan elde edilen veriler üzerinde Yapay zeka yöntemlerini uygulayarak gerçek deneyime en yakın değerlerin elde edilmesi için yapılacak geliştirme bir başka çalışma konusu olarak durmaktadır.

$\mathrm{Bu}$ çalışmanın devamı niteliğindeki çalışmamızda, burada önerdiğimiz işlevleri barındıran bir modeli benimseyen mobil uygulamayı geliştirmeyi planlamaktayı.

\section{Kaynakça}

[1] Zhao, S., Zhuang, Z., Ran, J., Lin, J., Yang, G., Yang, L., \& He, D. (2020). The association between domestic train transportation and novel coronavirus (2019-nCoV) outbreak in China from 2019 to 2020: a data-driven correlational report. Travel Medicine and Infectious Disease, 33, 101568.

[2] Gülhan, G., \& YİĞİT, H. İ. (2018). Taksi duraklarının konum ve kapasitelerinin, erişilebilirlik ölçütleri ve nüfus dağılımı kapsamında değerlendirilmesi: Tekirdağ-Çorlu örneği.Iğdır Üniversitesi Fen Bilimleri Enstitüsü Dergisi, 8(3), 153-166.

[3] TUHİ, İBB Ulaşım Raporu (2017), https://tuhim.ibb.gov.tr/\%C4\%B0statistiksel-

bilgiler/\%C4\%B0bb-ula\%C5\%9Fim-raporu-2017/(Erişim Tarihi: 01.12.2020)

[4] İBB (2020) AÇIK VERİ PORTALI, YOLCULUK TÜRÜ BAZINDA YOLCU SAYISI, https://data.ibb.gov.tr/dataset/yolculuk-turu-bazinda-yolcusayisi/resource/c2c6cec1-ceb5-4fab-8d87c5d900a99809(Erișim Tarihi: 05.12.2020)

[5] Habertürk (2016) İstanbul Toplu Ulaşım İstatistikleri, https://www.haberturk.com/istanbulda-trafigindeki-17-bintaksiden-sikyet-bitmiyor-1768602(Erişim Tarihi: 01.12.2020)

[6] İETT (2019) İSTANBULDA TOPLU ULAŞIM, https://www.iett.istanbul/tr/main/pages/istanbulda-topluulasim/95 (Erişim Tarihi: 01.12.2020)

[7] DHA (2019) İstanbul'da Organize Taksi Dolandırıcılığ Haberi, https://www.dha.com.tr/son-dakika/istanbuldaorganize-taksi-dolandiriciligi-23-gozalti-genis-haber/haber1671778(Erişim Tarihi: 01.12.2020)

[8] NTV (2020) Beyaz Masa Taksi Şikayetleri, https://www.ntv.com.tr/turkiye/beyaz-masaya-gunde-490taksi-sikayeti-geliyor-yolcu-secme-ters-cevap-vermebo,cjuct8Dj70C5OhmduujKWQ(Erişim Tarihi: 01.12.2020)

[9] ŞIKKAYETVAR (2020) Taksi Şikayetleri, https://www.sikayetvar.com/taksi-soforleri-odasi (Erişim tarihi: 22.07.2020)

[10] Milliyet (2020) Beyaz Masa’ya günde 490 şikâyet geliyor, https://www.milliyet.com.tr/gundem/beyaz-masaya-gunde490-sikayet-geliyor-6135649(Erişim Tarihi: 01.12.2020) 
[11] Uber:

https://play.google.com/store/apps/details?id=com.ubercab\& $\mathrm{gl}=\mathrm{TR}$ (Erişim Tarihi: 05.12.2020)

[12] Bolt:

https://play.google.com/store/apps/details?id=ee.mtakso.clie nt\&gl=TR (Erişim Tarihi: 05.12.2020)

[13] Careem:

https://play.google.com/store/apps/details?id=com.careem.a cma\&gl=TR (Erişim Tarihi: 05.12.2020)

[14] FreeNow TaxiBookingApp:

https://play.google.com/store/apps/details?id=taxi.android.cl ient\&gl=TR (Erişim Tarihi: 05.12.2020)

[15] Cabify:

https://play.google.com/store/apps/details?id=com.cabify.rid er\&gl=TR (Erişim Tarihi: 05.12.2020)

[16] iTaksi:

https://play.google.com/store/apps/details?id=tr.gov.ibb.itaks $\mathrm{i} \& \mathrm{hl}=\operatorname{tr}($ Erişim Tarihi: 05.12 .2020$)$

[17] BiTaksi:

https://play.google.com/store/apps/details?id=com.bitaksi.m usteri\&hl $=\operatorname{tr}($ Erişim Tarihi: 05.12.2020)

[18] ENTaksi:

https://play.google.com/store/apps/details?id=com.taksim.an droid\&hl=tr(Erişim Tarihi: 05.12 .2020$)$

[19] TezzTaksi:

https://play.google.com/store/apps/details?id=com.tezztaxise rvice.driver\&hl=tr(Erişim Tarihi: 05.12.2020)

[20] OTaksi:

https://play.google.com/store/apps/details?id=com.etaximo.a ndroid.clientapp. wlotaksi\&hl=tr(Erişim Tarihi: 05.12.2020)

[21]istTaksi-Taksimetre:

https://play.google.com/store/apps/details?id=com.tildadev.t aksimetre\&hl=tr(Erişim Tarihi: 05.12.2020)

[22] Taksi Fare\&Meter:

https://play.google.com/store/apps/details?id=com.hainva.ca lltaxi\&hl=tr(Erişim Tarihi: 05.12.2020)

[23] Taxi Fare Calculator:

https://play.google.com/store/apps/details?id=taxifare.japant axi.co.jp\&hl=tr(Erişim Tarihi: 05.12.2020)

[24] TAXImet- Taximeter:

https://play.google.com/store/apps/details?id=com.innovemi nd.taximeter \&hl=tr(Erişim Tarihi: 05.12.2020)

[25] Google Play Search (2020a)

https://play.google.com/store/search?q=cab\%20booking\%20app $\& \mathrm{c}=$ apps\&gl=TR(Erişim Tarihi: 04.10 .2020$)$

[26] Google Play Search (2020b)

https://play.google.com/store/search?q=taxi\%20booking\%20app $\& \mathrm{c}=$ apps\&gl=TR (Erişim Tarihi: 04.10.2020)

[27] Google Play Search (2020c)

https://play.google.com/store/search?q=taxi\%20booking\&c=app $\mathrm{s} \& \mathrm{gl}=\mathrm{TR}$ (Erişim Tarihi: 04.10.2020)

[28] Google Play Search (2020d)

https://play.google.com/store/search?q=taxi+taksi+cab+game\&c=apps (Erişim Tarihi: 01.10.2020)

[29] Google Play Search (2020e)

https://play.google.com/store/search?q=taxi\%20taksi\%20cab\%2 0-game\&c=apps\&gl=TR(Erişim Tarihi: 29.09 .2020 )

[30] Sharma, S. (2016). Mobile application to auto calculate taxi and microbus fare, Doctoral Dissertation, TribhuvanUniversity.

[31] Shrestha, A. M. (2013). KTM Taxi Meter, An android application, Doctoral Dissertation, Kathmandu University
[32] Osswald, S., Brueckel, N., Brickwedde, C., Lienkamp, M., \&Schoell, M. (2014, September). TaxiChecker: A mobile application for real-time taxi fare analysis. in adjunct proceedings of the 6th International Conference on Automotive User Interfacesand Interactive Vehicular Applications (pp. 1-6).

[33] Li, Y., Lu, J., Zhang, L., \&Zhao, Y. (2017). Taxi booking mobile app order demand prediction based on short-term traffic forecasting. Transportation Research Record, 2634(1), 57-68.

[34] Samarasekara, D. P. (2015). Mobile application for locate and contact nearest taxies via GPS, Doctoral Dissertation

[35] Noulas, A., Salnikov, V., Hristova, D., Mascolo, C., \&Lambiotte, R. (2018, October). Developing and deploying a taxi price comparison mobile app in the wild: Insights and challenges. In 2018 IEEE 5th International Conference on Data Science and Advanced Analytics (DSAA) (pp. 424433). IEEE.

[36] Adewumi, A., Odunjo, V., \&Misra, S. (2015). Developing a mobile application for taxi service company in Nigeria. In 2015 International Conference on Computing, Communicationand Security (ICCCS) (pp. 1-5). IEEE.

[37] Wenjie, C. (2014). Technical improvements on mobile app based taxi dispatching system. In 3rd International Conference on Computer Science and Service System. Atlantis Press.

[38] Zhang, L., Hu, T., Min, Y., Wu, G., Zhang, J., Feng, P., ... \& Ye, J. (2017). A taxi order dispatch model based on combinatorial optimization. In Proceedings of the 23rd ACM SIGKDD International Conference on Knowledge Discovery and Data Mining (pp. 2151-2159).

[39] Zhou, P., Nadeem, T., Kang, P., Borcea, C., \&Iftode, L. (2005). EZCab: A cab booking application using short-range wireless communication. In Third IEEE International Conference on Pervasive Computing and Communications (pp. 27-38). IEEE.

[40] Viala, A. (2013). Expanding and developing the android application for a private taxi start-up, Master's Thesis, Universitat Politècnica de Catalunya

[41] Zhang, D., He, T., Liu, Y., \&Stankovic, J. A. (2013). CallCab: A unified recommendation system for car pooling and regular taxi cab services. In 2013 IEEE International Conference on Big Data (pp. 439-447). IEEE.

[42] Sinh, N. V. (2017). Mobile application for taxi service, Doctoral Dissertation, International University-HCMC.

[43] Stat Counter, (2020) Mobile operating system market share Turkey, https://gs.statcounter.com/os-marketshare/mobile/turkey(Erişim Tarihi: 01.12.2021)

[44] Uber Web, Yardım ve Dokümantasyon, https://www.uber.com/tr/tr/ (Erişim Tarihi: 05.12.2020)

[45] Cabify Web, Yardım ve Dokümantasyon, https://cabify.com/en (Erişim Tarihi: 05.12.2020)

[46] FreeNow Web, Yardım ve Dokümantasyon, https://freenow.com/uk/ (Erişim Tarihi: 05.12.2020)

[47] Bolt Web, Yardım ve Dokümantasyon, https://bolt.eu/en/ (Erişim Tarihi: 05.12.2020)

[48] Careem Web, Yardım ve Dokümantasyon, https://www.careem.com/ (Erişim Tarihi: 05.12.2020)

[49] iTaksi Web, Yardım ve Dokümantasyon, https://www.itaksi.com/, (Erişim Tarihi: 05.12.2020)

[50] biTaksi Web, Yardım ve Dokümantasyon, http://www.bitaksi.com/ (Erişim Tarihi: 05.12.2020) 
[51] ENTaksi Web, Yardım ve Dokümantasyon, www.entaksi.com.tr (Erişim Tarihi: 05.12.2020)

[52] OTaksi Web, Yardım ve Dokümantasyon, https://otaksi.net/ (Erişim Tarihi: 05.12.2020)

[53] Taxi Fare Calculator Web, Yardım ve Dokümantasyon, https://japantaxi.co.jp/ (Erişim Tarihi: 05.12.2020)

[54] TAXImet- Taximeter Web, Yardım ve Dokümantasyon, https://www.taximet.com/ (Erişim Tarihi: 05.12.2020)

[55]Cabify'ın bazı işlevleri: a history of Mobility with Impact, Sustainability Report 2018, Cabify 2018

[56]Freenow'in bazı işlevleri: https://www.youtube.com/watch?v=Z7UEJc0zyg\&t=87s(Erişim Tarihi: 01.12 .2021$)$

[57] Cabify'ın bazı https://www.youtube.com/watch?v=ic3JTTaDJy0(Erişim Tarihi: 01.12.2020)

[58] Cabify'ın bazı işlevleri: https://www.youtube.com/watch?v=49kvZ3odnEM(Erişim Tarihi: 01.12.2020)

[59] Cabify'ın bazı işlevleri: https://www.youtube.com/watch?v=xDZpO0aow3U(Erişim Tarihi: 01.12.2020)

[60] Cabify'ın bazı işlevleri: https://www.youtube.com/watch?v=_3wC1WdjXEI(Erişim Tarihi: 01.12.2020)

[61] Uber'in bazı işlevleri: https://www.youtube.com/watch?v=9hvBQb3-tvM(Erişim Tarihi: 01.12.2020)

[62] Uber'in bazı işlevleri: https://www.youtube.com/watch?v=aDnydKz7k00(Erişim Tarihi: 01.12.2020)

[63] Uber'in bazı işlevleri: https://www.youtube.com/watch?v=xKXoqIgvFYY(Erişim Tarihi: 01.12.2020)

[64] BiTaksi'nin bazı işlevleri:https://www.youtube.com/watch?v=bpket0WcIF0( Erişim Tarihi: 01.12.2020)

[65]Bolt'un bazı işlevleri: https://www.youtube.com/watch?v=lqhKXIYOZ8o(Erişim Tarihi: 01.12.2020)

[66]Bolt'un baz1 işlevleri: https://www.youtube.com/watch?v=GWn546dBIXw(Erişim Tarihi: 01.12.2020)

[67] Bolt'un bazı işlevleri: https://www.youtube.com/watch?v=ehw5UiTzd1w(Erişim Tarihi: 01.12.2020)

[68] Careem'in bazı işlevleri: https://www.youtube.com/watch?v=ldPq8Laaay8(Erişim Tarihi: 01.12.2020)

[69] Careem'in bazı işlevleri: https://www.youtube.com/watch?v=YXFDJdye40U\&t(Erişi m Tarihi: 01.12.2020)

[70] Careem'in bazı işlevleri: https://www.youtube.com/watch?v=dw7Dwfpec-g(Erişim Tarihi: 01.12.2020)

[71] Chen, L., Mislove, A., \& Wilson, C. (2015). Peeking beneath the hood of uber. In Proceedings of the 2015 Internet Measurement Conference (pp. 495-508).

[72] Engels, A., \& Jansson, A. (2015). A data driven approach of optimizing the handling of limousine drivers in Dubai.

[73]SensorTower, Top TaxiApp, https://sensortower.com/blog/top-ridesharing-and-taxi-appsworldwide-december-2019(Erişim Tarihi: 05.12.2020)
[74]SensorTower, Top

TaxiApp, https://sensortower.com/blog/top-ridesharing-and-taxi-appsworldwide-november-2019(Erişim Tarihi: 05.12.2020)

[75]Marriott Bonvoy Traveller, Top TaxiApp, https://traveler.marriott.com/tips-and-trends/the-best-taxiand-ride-hailing-apps-around-the-world/(Erişim Tarihi: 05.12.2020)

[76] UBER, Uber Dinamik Ücretlendirme Modeli,https://www.uber.com/en-AE/blog/uber-dynamicpricing-model/(Erişim Tarihi: 01.12.2020)

[77] Google Maps Platform, https://developers.google.com/maps/documentation (Erişim Tarihi: 05.12.2020

[78] Google Directions Api,
https://developers.google.com/maps/documentation/directio ns/overview (Erişim Tarihi: 05.12.2020)

[79] Cetin, T., Deakin, E. (2019). Regulation of taxis and the rise of ride sharing. Transport Policy, 76, 149-158. 
Tablo 3.a. Yolculuk Öncesi Yolculuk Tasarımı (Yolculuk Hakkında Ön Bilgilendirmeye Dayalı Model) Aşaması

\begin{tabular}{|c|c|c|c|c|c|}
\hline İşlem ve İşlevler \Uygulamalar & Uber & $\begin{array}{c}\text { Bolt } \\
\text { (Taxify) }\end{array}$ & $\begin{array}{c}\text { Careem } \\
\text { Taksi }\end{array}$ & $\begin{array}{c}\text { FreeNow - } \\
\text { TaxiBookingApp }\end{array}$ & Cabify \\
\hline $\begin{array}{l}\text { Başlangıç ve Bitiş Adreslerine Göre Yolculuk Rotası } \\
\text { Hesaplamak ve Haritada Göstermek }\end{array}$ & $\checkmark$ & $\checkmark$ & $\checkmark$ & $\checkmark$ & $\checkmark$ \\
\hline $\begin{array}{l}\text { Başlangıç ve Bitiş Adreslerine Göre Alternatif Yolculuk } \\
\text { Rotalarını Hesaplamak ve Haritada Göstermek }\end{array}$ & $\mathbf{x}$ & $\mathbf{x}$ & $\mathbf{x}$ & $\mathbf{x}$ & $\mathbf{x}$ \\
\hline Duraklı Rota Hesaplayabilmek & $\checkmark$ & $\checkmark$ & $x$ & $\mathbf{x}$ & $x$ \\
\hline $\begin{array}{l}\text { Geçmiş Yolculuklarındaki Rotalarını ya da Favori Rotalarını } \\
\text { Görüntülemek }\end{array}$ & $\checkmark$ & $\mathbf{x}$ & $\mathbf{x}$ & $\mathbf{x}$ & $\mathbf{x}$ \\
\hline $\begin{array}{l}\text { Rotadaki Genel Trafik Durumunu Haritada Göstermek (Rota } \\
\text { Üzerindeki Trafik Akış ve Sıkışılıklarını Göstermek) }\end{array}$ & $\mathbf{x}$ & $\mathbf{x}$ & $\checkmark$ & $\mathbf{x}$ & $\mathbf{x}$ \\
\hline Rota İçin Toplam Yolculuk Mesafesini Hesaplamak & $\mathbf{x}$ & $x$ & $\mathbf{x}$ & $\checkmark$ & \\
\hline Rota için $\underline{\text { Tahmini }}$ Toplam Yolculuk Süresi Hesaplamak & $\checkmark$ & $\checkmark$ & $\checkmark$ & $\checkmark$ & $\checkmark$ \\
\hline $\begin{array}{l}\text { Rota için Tahmini Toplam Yolculuk Ücreti Hesaplamak } \\
\text { (Taksimetre ölçümüne dayalı tahmini ücretlendirme) }\end{array}$ & $\mathbf{x}$ & $\mathbf{x}$ & $\checkmark$ & $\checkmark$ & $\checkmark$ \\
\hline $\begin{array}{l}\text { Rota İçin Uygulanacak Nihai Ücreti yolculuk öncesi } \\
\text { hesaplamak (Dinamik } \tilde{\text { Ucretlendirme) }}\end{array}$ & $\checkmark$ & $\checkmark$ & $\mathbf{x}$ & $\mathbf{x}$ & $\mathbf{x}$ \\
\hline Taksi Tipi Seçmek & $\checkmark$ & $\checkmark$ & $\checkmark$ & $\checkmark$ & $\checkmark$ \\
\hline 5+ Yolcu Kapasiteli Araç Talep Etme & $\checkmark$ & $\checkmark$ & $x$ & $\checkmark$ & $\checkmark$ \\
\hline $\begin{array}{l}\text { Yolculuğun Tahmini Bitiş Süresini ve Gecikmeler Halinde } \\
\text { Oluşabilecek Son Bitiş Süresini Göstermek }\end{array}$ & $\checkmark$ & $\mathbf{x}$ & $\mathbf{x}$ & $\mathbf{x}$ & $\mathbf{x}$ \\
\hline İleri Bir Zaman Dilimi İçin Yolculuk Planlamak & $\checkmark$ & $\checkmark$ & $\checkmark$ & $\checkmark$ & $\checkmark$ \\
\hline Favori Rotaları Görüntüleme (Gösterme) & $\checkmark$ & $\mathbf{x}$ & $x$ & $x$ & $x$ \\
\hline
\end{tabular}

Tablo 3.b. Yolculuk Öncesi Yolculuk Tasarımı (Yolculuk Hakkında Ön Bilgilendirmeye Dayalı Model) Aşaması

\begin{tabular}{|c|c|c|c|c|c|}
\hline İşlem ve İşlevler \Uygulamalar & iTaksi & EN Taksi & Tezz Taksi & BiTaksi & OTaksi \\
\hline $\begin{array}{l}\text { Başlangıç ve Bitiş Adreslerine Göre Yolculuk Rotası Hesaplamak ve } \\
\text { Haritada Göstermek }\end{array}$ & $\checkmark$ & $\checkmark$ & $\checkmark$ & $\checkmark$ & $\checkmark$ \\
\hline $\begin{array}{l}\text { Başlangıç ve Bitiş Adreslerine Göre Alternatif Yolculuk Rotalarını } \\
\text { Hesaplamak ve Haritada Göstermek }\end{array}$ & $\mathbf{x}$ & $\mathbf{x}$ & $\mathbf{x}$ & $\mathbf{x}$ & $\mathbf{x}$ \\
\hline Durakl1 Rota Hesaplayabilmek & $x$ & $\mathrm{x}$ & $x$ & $x$ & $\checkmark$ \\
\hline $\begin{array}{l}\text { Geçmiş Yolculuklarındaki Rotalarını ya da Favori Rotalarını } \\
\text { Görüntülemek }\end{array}$ & $\mathbf{x}$ & $\mathbf{x}$ & $\mathbf{x}$ & $\mathbf{x}$ & $\mathbf{x}$ \\
\hline $\begin{array}{l}\text { Rotadaki Genel Trafik Durumunu Haritada Göstermek (Rota Üzerindeki } \\
\text { Trafik Akış ve Sıkışıklıklarını Göstermek) }\end{array}$ & $x$ & $\mathbf{x}$ & $\mathbf{x}$ & $\mathbf{x}$ & $\mathbf{x}$ \\
\hline Rota İçin Toplam Yolculuk Mesafesini Hesaplamak & $\checkmark$ & $\checkmark$ & $\checkmark$ & 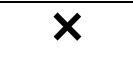 & $\checkmark$ \\
\hline Rota için Tahmini Toplam Yolculuk Süresi Hesaplamak & $\checkmark$ & $\checkmark$ & $\checkmark$ & $\checkmark$ & $\checkmark$ \\
\hline
\end{tabular}


Rota için Tahmini Toplam Yolculuk Ücreti Hesaplamak (Taksimetre ölçümüne dayalı tahmini ücretlendirme)

Rota İçin Uygulanacak Nihai Ücreti yolculuk öncesi hesaplamak (Dinamik Ücretlendirme)

Taksi Tipi Seçmek (Sarı, Turkuaz, Siyah)

5+ Yolcu Kapasiteli Araç Talep Etme

Yolculuğun Tahmini Bitiş Süresini ve Gecikmeler Halinde Oluşabilecek Son Bitiş Süresini Göstermek

İleri Bir Zaman Dilimi İçin Yolculuk Planlamak

Favori Rotaları Görüntüleme (Gösterme)

\begin{tabular}{c|c|c|c|c}
$\checkmark$ & $\checkmark$ & $\checkmark$ & $\checkmark$ & $\checkmark$ \\
\hline & $x$ & $x$ & $x$ & $x$ \\
\hline$x$ & $x$ & $x$ & $x$ & $x$ \\
\hline$x$ & $x$ & $x$ & $x$ & $x$ \\
\hline$x$ & $x$ & $\checkmark$ & $x$ & $\checkmark$ \\
\hline$x$ & $x$ & $x$ & $x$ & $x$ \\
\hline
\end{tabular}

Tablo 3.c. Yolculuk Öncesi Yolculuk Tasarımı (Yolculuk Hakkında Ön Bilgilendirmeye Dayalı Model) Aşaması

\section{İşlem ve İşlevler \Uygulamalar}

Başlangıç ve Bitiş Adreslerine Göre Yolculuk Rotası Hesaplamak ve Haritada Göstermek

Başlangıç ve Bitiş Adreslerine Göre Alternatif Yolculuk Rotalarını Hesaplamak ve Haritada Göstermek

Duraklı Rota Hesaplayabilmek

Geçmiş Yolculuklarındaki Rotalarını ya da Favori Rotalarını Görüntülemek

Rotadaki Genel Trafik Durumunu Haritada Göstermek (Rota Üzerindeki Trafik Akış ve Sıkışıklıklarını Göstermek)

Rota İçin Toplam Yolculuk Mesafesini Hesaplamak

Rota için Tahmini Toplam Yolculuk Süresi Hesaplamak

Rota için Tahmini Toplam Yolculuk Ücreti Hesaplamak (Taksimetre ölçümüne dayalı tahmini ücretlendirme)

Rota İçin Uygulanacak Nihai Ücreti yolculuk öncesi hesaplamak (Dinamik Ücretlendirme)

Taksi Tipi Seçmek (Sarı, Turkuaz, Siyah)

\section{5+ Yolcu Kapasiteli Araç Talep Etme}

Yolculuğun Tahmini Bitiş Süresini ve Gecikmeler Halinde Oluşabilecek Son Bitiş Süresini Göstermek

İleri Bir Zaman Dilimi İçin Yolculuk Planlamak

Favori Rotaları Görüntüleme (Gösterme)

\begin{tabular}{|c|c|c|}
\hline İstTaksi- Taksimetre & Taxi Fare \& Meter & $\begin{array}{l}\text { Taksi Fare } \\
\text { Calculator }\end{array}$ \\
\hline$\checkmark$ & $\checkmark$ & $\checkmark$ \\
\hline$x$ & $\checkmark$ & $x$ \\
\hline$x$ & $x$ & $x$ \\
\hline$x$ & $x$ & $x$ \\
\hline$x$ & $x$ & $x$ \\
\hline$\checkmark$ & $\checkmark$ & $\checkmark$ \\
\hline$\checkmark$ & $\checkmark$ & $\checkmark$ \\
\hline$\checkmark$ & $\checkmark$ & $\checkmark$ \\
\hline$x$ & $x$ & $x$ \\
\hline$x$ & $x$ & $x$ \\
\hline$x$ & $x$ & $x$ \\
\hline$x$ & $x$ & $x$ \\
\hline$x$ & $x$ & $x$ \\
\hline$x$ & $x$ & $x$ \\
\hline
\end{tabular}


Tablo 4.a. Yolculuk Eşleştirme Aşaması ve İlgili Aşamanın Geçiş İşlemleri (Sarı arka plan renkli)

\begin{tabular}{|c|c|c|c|c|c|c|c|c|c|c|c|c|c|c|c|c|c|}
\hline \multicolumn{3}{|c|}{ İşlem ve İşlevler \Uygulamalar } & \multicolumn{3}{|c|}{ Uber } & \multicolumn{3}{|c|}{ Bolt (Taxify) } & \multicolumn{3}{|c|}{ Careem Taksi } & \multicolumn{3}{|c|}{\begin{tabular}{|c|} 
FreeNow - \\
TaxiBookingApp
\end{tabular}} & \multicolumn{3}{|c|}{ Cabify } \\
\hline \multicolumn{3}{|c|}{ Yolculuk Yapma Onayı } & \multicolumn{3}{|c|}{$\checkmark$} & \multicolumn{3}{|c|}{$\checkmark$} & \multicolumn{3}{|c|}{$\checkmark$} & \multicolumn{3}{|c|}{$\checkmark$} & \multicolumn{3}{|c|}{$\checkmark$} \\
\hline \multicolumn{3}{|c|}{$\begin{array}{l}\text { Alternatif Rotalar Arasından Rota Seçmek } \\
\text { (Geçmiş Yolculuk Rotaları, Hesaplanan Alternatif } \\
\text { Rotalar, Favori Rotalar }\end{array}$} & \multicolumn{3}{|c|}{$x$} & \multicolumn{3}{|c|}{$\mathbf{x}$} & \multicolumn{3}{|c|}{$x$} & \multicolumn{3}{|c|}{$\mathbf{x}$} & \multicolumn{3}{|c|}{$\mathbf{x}$} \\
\hline \multicolumn{3}{|c|}{ Taksi ile Yolcu Arasındaki Mesafeyi Gösterme } & \multicolumn{3}{|c|}{$x$} & \multicolumn{3}{|c|}{$x$} & \multicolumn{3}{|c|}{$\checkmark$} & \multicolumn{3}{|c|}{$\checkmark$} & \multicolumn{3}{|c|}{$?$} \\
\hline \multicolumn{3}{|c|}{ Kapsam Alanı İçindeki Taksileri Görüntüleme } & \multicolumn{3}{|c|}{$\checkmark$} & \multicolumn{3}{|c|}{$\checkmark$} & \multicolumn{3}{|c|}{$\checkmark$} & \multicolumn{3}{|c|}{$\checkmark$} & \multicolumn{3}{|c|}{$\checkmark$} \\
\hline Bebek Koltuğu & Evcil Hayvan & $\begin{array}{l}\text { Engelli } \\
\text { Yolcu }\end{array}$ & $\mathbf{x}$ & $\checkmark$ & $\checkmark$ & $\checkmark$ & $\checkmark$ & $x$ & $\checkmark$ & $x$ & $x$ & $x$ & $\mathbf{x}$ & $\checkmark$ & $\checkmark$ & $\mathbf{x}$ & $\checkmark$ \\
\hline \multicolumn{3}{|c|}{$\begin{array}{l}\text { Taksi Araç Gövde Tipi (Segmenti) Seçme (Sedan, } \\
\text { Station Wagon, vb.) }\end{array}$} & \multicolumn{3}{|c|}{$\checkmark$} & \multicolumn{3}{|c|}{$\checkmark$} & \multicolumn{3}{|c|}{$\checkmark$} & \multicolumn{3}{|c|}{$\checkmark$} & & $\checkmark$ & \\
\hline $\begin{array}{l}\text { Kapsama Alanır } \\
\text { İçin Seçme }\end{array}$ & aki bir Taksiyi Y & luk Yapmak & & $x$ & & & $x$ & & & $\mathbf{x}$ & & & $x$ & & & $x$ & \\
\hline $\begin{array}{l}\text { Tercih edeceği } \\
\text { imkanı sunmak }\end{array}$ & da favori şoför & yolculuk & & $x$ & & & $x$ & & & $\mathbf{x}$ & & & $\checkmark$ & & & $x$ & \\
\hline Yolculuğu Diğer & olcularla Paylaş & & & $\checkmark$ & & & $x$ & & & $x$ & & & $?$ & & & $x$ & \\
\hline Kapsama Alanır & Genişletme Ve & altma & & $x$ & & & $x$ & & & $x$ & & & $x$ & & & $x$ & \\
\hline
\end{tabular}

Tablo 4.b. Yolculuk Eşleştirme Aşaması ve İlgili Aşamanın Geçiş İşlemleri (Sarı arka plan renkli)

\begin{tabular}{|c|c|c|c|c|c|c|c|c|c|c|c|c|c|c|c|c|c|}
\hline \multicolumn{3}{|c|}{ İşlem ve İşlevler \Uygulamalar } & \multicolumn{3}{|c|}{ iTaksi } & \multicolumn{3}{|c|}{ EN Taksi } & \multicolumn{3}{|c|}{ Tezz Taksi } & \multicolumn{3}{|c|}{ BiTaksi } & \multicolumn{3}{|c|}{ OTaksi } \\
\hline \multicolumn{3}{|c|}{ Yolculuk Yapma Onayı } & \multicolumn{3}{|c|}{$\checkmark$} & \multicolumn{3}{|c|}{$\checkmark$} & \multicolumn{3}{|c|}{$\checkmark$} & \multicolumn{3}{|c|}{$\checkmark$} & \multicolumn{3}{|c|}{$\checkmark$} \\
\hline \multicolumn{3}{|c|}{$\begin{array}{l}\text { Alternatif Rotalar Arasından Rota Seçmek (Geçmişş } \\
\text { Yolculuk Rotaları, Hesaplanan Alternatif Rotalar, } \\
\text { Favori Rotalar }\end{array}$} & \multicolumn{3}{|c|}{$\mathbf{x}$} & \multicolumn{3}{|c|}{$\mathbf{x}$} & \multicolumn{3}{|c|}{$\mathbf{x}$} & \multicolumn{3}{|c|}{$\mathbf{x}$} & \multicolumn{3}{|c|}{$x$} \\
\hline \multicolumn{3}{|c|}{ Taksi ile Yolcu Arasındaki Mesafeyi Gösterme } & \multicolumn{3}{|c|}{$\checkmark$} & \multicolumn{3}{|c|}{$\checkmark$} & \multicolumn{3}{|c|}{$\checkmark$} & \multicolumn{3}{|c|}{$\checkmark$} & \multicolumn{3}{|c|}{$\checkmark$} \\
\hline \multicolumn{3}{|c|}{ Kapsam Alanı İçindeki Taksileri Görüntüleme } & \multicolumn{3}{|c|}{$\checkmark$} & \multicolumn{3}{|c|}{$\checkmark$} & \multicolumn{3}{|c|}{$\checkmark$} & \multicolumn{3}{|c|}{$\checkmark$} & \multicolumn{3}{|c|}{$\checkmark$} \\
\hline Bebek Koltuğu & Evcil Hayvan & Engelli Yolcu & $\mathbf{x}$ & $\mathbf{x}$ & $\mathbf{x}$ & $x$ & $\mathbf{x}$ & $\mathbf{x}$ & $\checkmark$ & $\checkmark$ & $\checkmark$ & $\mathbf{x}$ & $\mathbf{x}$ & $\mathbf{x}$ & $\mathbf{x}$ & $\checkmark$ & $\bar{x}$ \\
\hline \multicolumn{3}{|c|}{$\begin{array}{l}\text { Taksi Araç Gövde Tipi (Segmenti) Seçme (Sedan, } \\
\text { Station Wagon, vb.) }\end{array}$} & \multicolumn{3}{|c|}{$\mathbf{x}$} & \multicolumn{3}{|c|}{$x$} & \multicolumn{3}{|c|}{$x$} & \multicolumn{3}{|c|}{$x$} & & $x$ & \\
\hline $\begin{array}{l}\text { Kapsama Alanı } \\
\text { İçin Seçme }\end{array}$ & daki bir Taksiyi & olculuk Yapmak & & $x$ & & & $x$ & & & $x$ & & & $x$ & & & $\checkmark$ & \\
\hline $\begin{array}{l}\text { Tercih edeceği } \\
\text { imkanı sunmak }\end{array}$ & a da favori şoför & e yolculuk & & $x$ & & & $x$ & & & $x$ & & & $x$ & & & $\checkmark$ & \\
\hline Yolculuğu Diğ & Yolcularla Payl & mak & & $x$ & & & $x$ & & & $x$ & & & $x$ & & & $x$ & \\
\hline Kapsama Alanı & 1 Genişletme Ve & araltma & & $x$ & & & $x$ & & & $x$ & & & $x$ & & & $x$ & \\
\hline
\end{tabular}


İşlem ve İşlevler \Uygulamalar

\begin{tabular}{c|c|c|c|c}
\hline Uber & Bolt (Taxify) & Careem Taksi & $\begin{array}{r}\text { FreeNow - } \\
\text { TaxiBookingApp }\end{array}$ & Cabify \\
\hline$\checkmark$ & $\checkmark$ & $\checkmark$ & $\checkmark$ & $\checkmark$ \\
$\times$ & $x$ & $x$ & $x$ & $x$ \\
$\checkmark$ & $\checkmark$ & $\checkmark$ & $\checkmark$ & $\checkmark$ \\
\hline$\times$ & $x$ & $x$ & $x$ & $x$ \\
\hline$\checkmark$ & $x$ & $\checkmark$ & $\checkmark$ & $\checkmark$ \\
\hline$\checkmark$ & $\checkmark$ & $\checkmark$ & $\checkmark$ & $\checkmark$ \\
\hline$\checkmark$ & $\checkmark$ & $\checkmark$ & $\checkmark$ & $?$ \\
\hline$\checkmark$ & $\checkmark$ & $\checkmark$ & $\checkmark$ & $\checkmark$ \\
\hline & & & $\checkmark$ & $\checkmark$ \\
\hline
\end{tabular}

Tablo 5.b. Taksi Bekleme Aşaması ve İlgili Aşamanın Geçiş Işslemleri (Sarı arka plan renkli)

\begin{tabular}{|c|c|c|c|c|c|}
\hline İşlem ve İşlevler \Uygulamalar & iTaksi & EN Taksi & Tezz Taksi & BiTaksi & OTaksi \\
\hline Taksi Çağırma & $\checkmark$ & $\checkmark$ & $\checkmark$ & $\checkmark$ & $\checkmark$ \\
\hline Taksi Durağıı Telefon İle Aratarak Taksi Çağırma & $x$ & $x$ & $x$ & $x$ & $x$ \\
\hline Kayıtllı araç filosu ve ağından & $x$ & $x$ & $x$ & $x$ & $x$ \\
\hline Mevcut taksi ağlarını kullanarak & $\checkmark$ & $\checkmark$ & $\checkmark$ & $\checkmark$ & $\checkmark$ \\
\hline Taksi ile Yolcu Arasındaki Anlık Mesafeyi Gösterme & $\checkmark$ & $x$ & $\checkmark$ & $\checkmark$ & $\checkmark$ \\
\hline $\begin{array}{l}\text { Yolcunun Taksi Çağırdığı Andan İtibaren Geçen Süreyi } \\
\text { Gösterme }\end{array}$ & $\checkmark$ & $\checkmark$ & $\checkmark$ & $\checkmark$ & $\checkmark$ \\
\hline Şoförü Arama (Voip) Veya Mesajlaşma & $\checkmark$ & $\checkmark$ & $?$ & $\checkmark$ & $\checkmark$ \\
\hline Taksinin Anlık Konumunu Gösterme & $\checkmark$ & $\checkmark$ & $\checkmark$ & $\checkmark$ & $\checkmark$ \\
\hline Taksi Çağrısını İptal Etme & $\checkmark$ & $\checkmark$ & $\checkmark$ & $\checkmark$ & $\checkmark$ \\
\hline
\end{tabular}

Tablo 6.a. Yolculuk Seyir Takibi (Yolcunun Yolculuğunu Kontrol Edebilmesini Săglayan Model- Yolculuk Seyir Takibi) Aşaması ile İlgili Aşamanın Geçiş İ̧lemleri (Sarı arka plan renkli)

\begin{tabular}{l|c|c|c|c|c|c}
\hline İșlem ve İşlevler \Uygulamalar & Uber & $\begin{array}{c}\text { Bolt } \\
\text { (Taxify) }\end{array}$ & $\begin{array}{c}\text { Careem } \\
\text { Taksi }\end{array}$ & $\begin{array}{c}\text { FreeNow - } \\
\text { TaxiBookingApp }\end{array}$ & $\begin{array}{c}\text { TAXImet- } \\
\text { Cabify } \\
\text { Taximeter }\end{array}$ \\
\hline Taksiye Binme ve Rotanın Şoföre Bildirilmesi & $\mathbf{X}$ & $\mathbf{X}$ & $\mathbf{X}$ & $\mathbf{X}$ & $\mathbf{X}$ & $\mathbf{X}$ \\
\hline Yolculuk Başlat Onayı & $\mathbf{X}$ & $\mathbf{X}$ & $\mathbf{X}$ & $\mathbf{X}$ & $\mathbf{X}$ & $\times$ \\
\hline Rotadaki Anlık Konumu Hesaplamak ve Göstermek & $\checkmark$ & $\checkmark$ & $\checkmark$ & $\checkmark$ & $\checkmark$ & $\times$ \\
\hline
\end{tabular}




\begin{tabular}{|c|c|c|c|c|c|c|}
\hline Rotadaki Anlık Toplam Yolculuk Süresini Hesaplamak & $x$ & $x$ & $x$ & $x$ & $?$ & $x$ \\
\hline Rotadaki Anlık Toplam Alınan Mesafeyi Hesaplamak & $\mathbf{x}$ & $\mathbf{x}$ & $x$ & $x$ & $?$ & $\checkmark$ \\
\hline Rotadaki Anlık Toplam Kalan Mesafeyi Hesaplamak & $\mathbf{x}$ & $\mathbf{x}$ & $\mathbf{x}$ & $\mathbf{x}$ & $?$ & $\mathbf{x}$ \\
\hline Anlık Toplam Ücret Hesaplamak & $\mathbf{x}$ & $\mathbf{x}$ & $\mathbf{x}$ & $\mathbf{x}$ & $?$ & $\checkmark$ \\
\hline Anlık Tahmini Kalan Yolculuk Süresi Hesaplamak & $\mathbf{x}$ & $x$ & $x$ & $x$ & $?$ & $x$ \\
\hline Rota Değiştirme İstemi Yapma & $\mathbf{x}$ & $\mathbf{x}$ & $\mathbf{x}$ & $\mathbf{x}$ & $?$ & $x$ \\
\hline Yolculuğu çevrimiçi ortamlarda paylaştırmak & $\checkmark$ & $\checkmark$ & $\checkmark$ & $x$ & $\checkmark$ & $x$ \\
\hline Varış Noktasını Değiştirmek & $\checkmark$ & $\checkmark$ & $\checkmark$ & $\checkmark$ & $?$ & $x$ \\
\hline Rotadaki Anlık Trafik Durumunu Göstermek- & $x$ & $x$ & $x$ & $\mathbf{x}$ & $\mathbf{x}$ & $x$ \\
\hline $\begin{array}{l}\text { Anlık Seyir Değişkenlerini Sonradan Erişim İçin } \\
\text { Kaydetmek (Konum) }\end{array}$ & $x$ & $x$ & $x$ & $x$ & $x$ & $x$ \\
\hline
\end{tabular}

Tablo 6.b. Yolculuk Seyir Takibi (Yolcunun Yolculuğunu Kontrol Edebilmesini Sağlayan Model- Yolculuk Seyir Takibi) Aşaması ile İlgili Aşamanın Geçiş Işlemleri (Sarı arka plan renkli)

\begin{tabular}{|c|c|c|c|c|c|}
\hline İşlem ve İşlevler \Uygulamalar & iTaksi & EN Taksi & Tezz Taksi & BiTaksi & OTaksi \\
\hline Taksiye Binme ve Rotanın Şoföre Bildirilmesi & $x$ & $x$ & $x$ & $x$ & $x$ \\
\hline Yolculuk Başlat Onayı & $\mathbf{x}$ & $\mathbf{x}$ & $\mathbf{x}$ & $\mathbf{x}$ & $?$ \\
\hline Rotadaki Anlık Konumu Hesaplamak ve Göstermek & $\checkmark$ & $\checkmark$ & $?$ & $\checkmark$ & $\checkmark$ \\
\hline Rotadaki Anlık Toplam Yolculuk Süresini Hesaplamak & $\mathbf{x}$ & $x$ & $?$ & $\mathbf{x}$ & $\mathbf{x}$ \\
\hline Rotadaki Anlık Toplam Alınan Mesafeyi Hesaplamak & $\mathbf{x}$ & $\mathbf{x}$ & $?$ & $\mathbf{x}$ & $\mathbf{x}$ \\
\hline Rotadaki Anlık Toplam Kalan Mesafeyi Hesaplamak & $\mathbf{x}$ & $x$ & $?$ & $\mathbf{x}$ & $x$ \\
\hline Anlık Toplam Ücret Hesaplamak & $\mathbf{x}$ & $\mathbf{x}$ & $?$ & $\mathbf{x}$ & $x$ \\
\hline Anlık Tahmini Kalan Yolculuk Süresi Hesaplamak & $x$ & $?$ & $?$ & $\mathbf{x}$ & $?$ \\
\hline Rota Değiştirmek & $x$ & $?$ & $?$ & $x$ & $x$ \\
\hline Yolculuğu çevrimiçi ortamlarda paylaştırmak & $x$ & $?$ & $\checkmark$ & $\checkmark$ & $x$ \\
\hline Varış Noktasını Değiştirmek & $?$ & $?$ & $?$ & $?$ & $?$ \\
\hline Rotadaki Anlık Trafik Durumunu Göstermek & $x$ & $x$ & $x$ & $x$ & $x$ \\
\hline Anlık Seyir Değişkenlerini Sonradan Erişim İçin Kaydetmek (Konum) & $\mathbf{x}$ & $\mathbf{x}$ & $\mathbf{x}$ & $\mathbf{x}$ & $\mathbf{x}$ \\
\hline
\end{tabular}


Tablo 7.a. Yolculuk Sonu ve Sonrası (Yolculuk Değerlendirme ve Gelecek Yolculuk İlişkilendirme İşlemleri) Aşaması ile İlgili Aşamanın Geçiş İşlemleri (Sarı arka plan renkli)

\begin{tabular}{l|c|c|c|c|c}
\hline İșlem ve İşlevler \ Uygulamalar & Uber & Bolt (Taxify) & $\begin{array}{c}\text { Careem } \\
\text { Taksi }\end{array}$ & $\begin{array}{c}\text { FreeNow - } \\
\text { TaxiBookingApp }\end{array}$ & Cabify \\
\hline Yolculuk Ücreti Ödemek & $\checkmark$ & $\checkmark$ & $\checkmark$ & $\checkmark$ & $\checkmark$ \\
\hline Online Ödeme, Kredi Kartı, vb. & $\checkmark$ & $\checkmark$ & $\checkmark$ & $\checkmark$ & $\checkmark$ \\
\hline Nakit & $\checkmark$ & $\checkmark$ & $\checkmark$ & $\checkmark$ & $\checkmark$ \\
\hline Acil Yolculuk Sonlandırma & $\checkmark$ & $\checkmark$ & $?$ & $?$ & $\checkmark$ \\
\hline Geçmiş Yolculukları Görüntüleme & $\checkmark$ & $\checkmark$ & $\checkmark$ & $\checkmark$ & $\checkmark$ \\
\hline Geçmiş Yolculuk Takip Dökümü Çıkarma & $\checkmark$ & $\checkmark$ & $\checkmark$ & $?$ & $?$ \\
\hline Favori Şoför Ekleme & $\checkmark$ & $\times$ & $\times$ & $\checkmark$ & $?$ \\
\hline Favori Konum (Adres) Ekleme & $\checkmark$ & $\checkmark$ & $\checkmark$ & $\checkmark$ & $\checkmark$ \\
\hline Favori Rota Ekleme & $\checkmark$ & $\times$ & $\times$ & $?$ & $?$ \\
\hline Son Alınan Hizmeti Değerlendirme & $\checkmark$ & $\checkmark$ & $\checkmark$ & $\checkmark$ & $\checkmark$ \\
\hline Şoför ile İletişime Geçebilme (Unutulan eşya, vb. nedenlerle) & $\checkmark$ & $\checkmark$ & $\times$ & $\checkmark$ & $\checkmark$ \\
\hline
\end{tabular}

Tablo 7.b. Yolculuk Sonu ve Sonrası (Yolculuk Değerlendirme ve Gelecek Yolculuk İlişkilendirme İşlemleri) Aşaması ile İlgili Aşamanın Geçiş İslemleri (Sarı arka plan renkli)

\begin{tabular}{l|c|c|c|c|c}
\hline İşlem ve İşlevler \Uygulamalar & iTaksi & EN Taksi & Tezz Taksi & BiTaksi & OTaksi \\
\hline Yolculuk Ücreti Ödemek & $\checkmark$ & $\checkmark$ & $\checkmark$ & $\checkmark$ & $\checkmark$ \\
\hline Online Ödeme, Kredi Kartı, vb. & $\checkmark$ & $\checkmark$ & $\checkmark$ & $\checkmark$ & $\checkmark$ \\
\hline Nakit & $\checkmark$ & $\checkmark$ & $\checkmark$ & $\checkmark$ & $\checkmark$ \\
\hline Acil Yolculuk Sonlandırma & $?$ & $?$ & $?$ & $?$ & $?$ \\
\hline Geçmiş Yolculukları Görüntüleme & $\checkmark$ & $\checkmark$ & $\checkmark$ & $\checkmark$ & $\checkmark$ \\
\hline Geçmiş Yolculuk Takip Dökümü Çıkarma & $?$ & $?$ & $?$ & $?$ & $?$ \\
\hline Favori Şoför Ekleme & $\times$ & $?$ & $?$ & $\times$ & $?$ \\
\hline Favori Konum (Adres) Ekleme & $\checkmark$ & $\checkmark$ & $\checkmark$ & $\checkmark$ & $\checkmark$ \\
\hline Favori Rota Ekleme & $\times$ & $\times$ & $\times$ & $\times$ & $?$ \\
\hline Son Alınan Hizmeti Değerlendirme & $\checkmark$ & $\checkmark$ & $\checkmark$ & $\checkmark$ & $\checkmark$ \\
\hline Şoför ile İletişime Geçebilme (Unutulan eşya, vb. nedenlerle) & $\times$ & $\checkmark$ & $?$ & $\checkmark$ & $\times$ \\
\hline
\end{tabular}

